\title{
Atmospheric effects and societal consequences of regional scale nuclear conflicts and acts of individual nuclear terrorism
}

\author{
O. B. Toon ${ }^{1}$, R. P. Turco ${ }^{2}$, A. Robock ${ }^{3}$, C. Bardeen ${ }^{1}$, L. Oman ${ }^{3}$, and G. L. Stenchikov ${ }^{3}$ \\ ${ }^{1}$ Department of Atmospheric and Oceanic Sciences, Laboratory for Atmospheric and Space Physics, University of Colorado, \\ Boulder, CO, USA \\ ${ }^{2}$ Department of Atmospheric and Oceanic Sciences, Univ. of California, Los Angeles, USA \\ ${ }^{3}$ Department of Environmental Sciences, Rutgers Univ., New Brunswick, NJ, USA
}

Received: 15 August 2006 - Published in Atmos. Chem. Phys. Discuss.: 22 November 2006

Revised: 14 March 2007 - Accepted: 2 April 2007 - Published: 19 April 2007

\begin{abstract}
We assess the potential damage and smoke production associated with the detonation of small nuclear weapons in modern megacities. While the number of nuclear warheads in the world has fallen by about a factor of three since its peak in 1986, the number of nuclear weapons states is increasing and the potential exists for numerous regional nuclear arms races. Eight countries are known to have nuclear weapons, 2 are constructing them, and an additional 32 nations already have the fissile material needed to build substantial arsenals of low-yield (Hiroshima-sized) explosives. Population and economic activity worldwide are congregated to an increasing extent in megacities, which might be targeted in a nuclear conflict. We find that low yield weapons, which new nuclear powers are likely to construct, can produce 100 times as many fatalities and 100 times as much smoke from fires per kt yield as previously estimated in analyses for full scale nuclear wars using high-yield weapons, if the small weapons are targeted at city centers. A single "small" nuclear detonation in an urban center could lead to more fatalities, in some cases by orders of magnitude, than have occurred in the major historical conflicts of many countries. We analyze the likely outcome of a regional nuclear exchange involving 10015 -kt explosions (less than $0.1 \%$ of the explosive yield of the current global nuclear arsenal). We find that such an exchange could produce direct fatalities comparable to all of those worldwide in World War II, or to those once estimated for a "counterforce" nuclear war between the superpowers. Megacities exposed to atmospheric fallout of long-lived radionuclides would likely be abandoned indefinitely, with severe national and international implications. Our analysis shows that smoke from urban firestorms in a regional war would rise into the upper troposphere due to pyro-convection. Robock et al. (2007) show that the smoke would subsequently rise deep into the
\end{abstract}

Correspondence to: O. B. Toon

(toon@lasp.colorado.edu) stratosphere due to atmospheric heating, and then might induce significant climatic anomalies on global scales. We also anticipate substantial perturbations of global ozone. While there are many uncertainties in the predictions we make here, the principal unknowns are the type and scale of conflict that might occur. The scope and severity of the hazards identified pose a significant threat to the global community. They deserve careful analysis by governments worldwide advised by a broad section of the world scientific community, as well as widespread public debate.

\section{Introduction}

In the 1980s, quantitative studies of the consequences of a nuclear conflict between the superpowers provoked international scientific and political debate, and deep public concern (Crutzen and Birks, 1982; Turco et al., 1983; Pittock et al., 1985). The resulting recognition that such conflicts could produce global scale damage at unacceptable levels contributed to an ongoing reduction of nuclear arsenals and improvements in relationships between the major nuclear powers. Here we discuss the effects of the use of a single nuclear weapon by a state or terrorist. We then provide the first comprehensive quantitative study of the consequences of a nuclear conflict involving multiple weapons between the emerging smaller nuclear states. Robock et al. (2007) explore the climate changes that might occur due to the smoke emissions from such a conflict.

The results of this study show that the potential effects of nuclear explosions having yields similar to those of the weapons used over Japan during the Second World War (WW-II) are, in relation to yield, unexpectedly large. At least eight countries are capable of transport and detonation of such nuclear devices. Moreover, North Korea appears to have a growing stockpile of warheads, and Iran is suspiciously pursuing uranium enrichment - a necessary precursor

Published by Copernicus GmbH on behalf of the European Geosciences Union. 

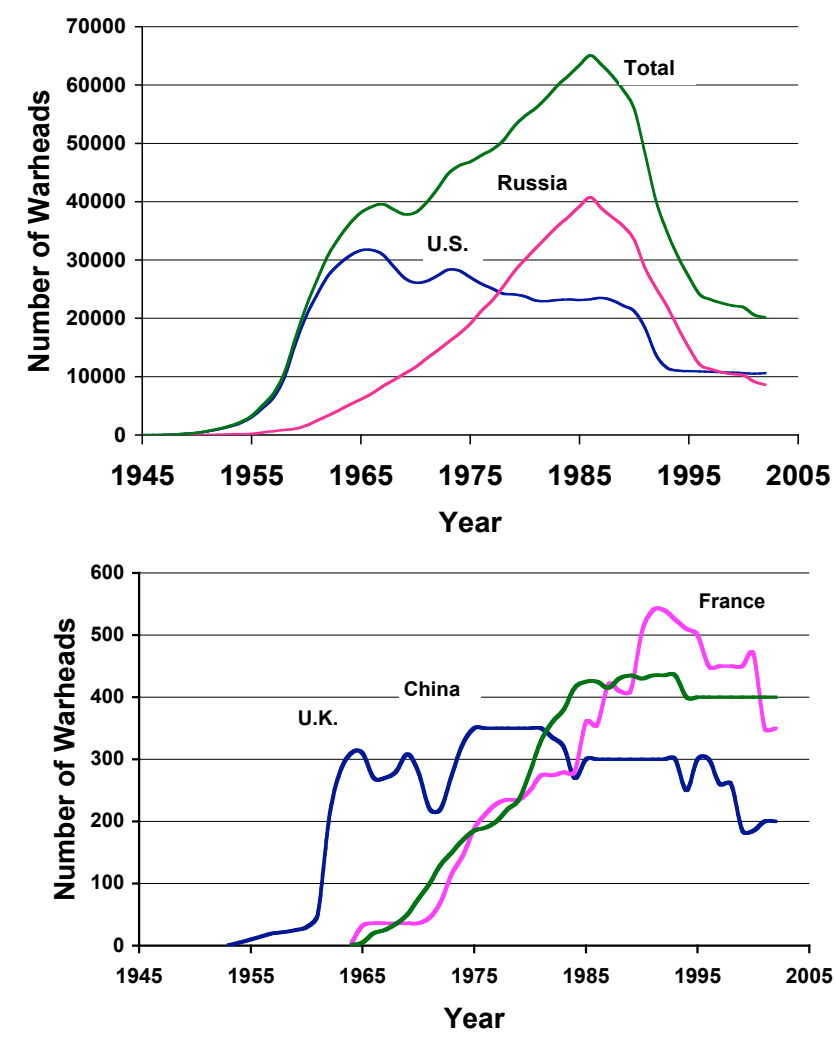

Fig. 1. (top): Number of nuclear warheads in Russia (USSR), the U.S. and the total for all the Nuclear Weapons States (Norris and Kristensen, 2002). (About 10000 Russian warheads of indeterminate status were omitted ). Russia and the U.S. have more than $95 \%$ of the warheads worldwide. The number of warheads began to fall after 1986 following the Intermediate-Range Nuclear Forces Treaty, and by 2002 was about one-third of its value at the peak in 1986. Current treaties do not require a future reduction in the numbers of warheads, only a reduction in the numbers of warheads that are on strategic delivery systems. (bottom): The arsenals of China, France and Britain have also remained stable or declined in the past two decades. Note the factor of about 100 change in scale between (top) and (bottom).

to weapons construction. Thirty-two other countries that do not now have nuclear weapons possess sufficient fissionable nuclear materials to construct weapons, some in a relatively short period of time. For these nations, a regional conflict involving modest numbers of 15-kiloton (kt, the TNT explosive yield equivalent) weapons to attack cities could cause casualties that exceed, in some cases by orders of magnitude, their losses in previous conflicts. Indeed, in some case, the casualties can rival previous estimates for a limited strategic war between the superpowers involving thousands of weapons carrying several thousand megatons $(\mathrm{Mt})$ of yield. Early radioactive fallout from small nuclear ground bursts would leave large sections of target areas contaminated and effectively uninhabitable. (Hiroshima and Nagasaki were attacked by airbursts, which will not deposit large amounts of local radiation unless it is raining. They were continuously inhabited.) Because of the smoke released in fires ignited by detonations, there is a possibility that 10015 -kt weapons used against city centers would produce global climate disturbances unprecedented in recorded human history (Robock et al., 2007). An individual in possession of one of the thousands of existing lightweight nuclear weapons could kill or injure a million people in a terrorist attack.

Below we first discuss the arsenals of the existing, and potential, nuclear powers. We then describe the casualties due to blast and to fires set by thermal radiation from an attack on a single megacity with one low yield nuclear weapon. Next we discuss the casualties if current and projected arsenals of such weapons were ever used in a regional conflict. We then discuss the impact of radioactive contamination. Finally, we describe the amounts of smoke that may be generated in a regional scale conflict. At the end of each of these sections we outline the associated uncertainties.

We have attempted to employ realistic scenarios in this analysis. However, we do not have access to the war plans of any countries, nor to verifiable data on existing nuclear arsenals, delivery systems, or plans to develop, build or deploy nuclear weapons. There are obviously many possible pathways for regional conflicts to develop. Opinions concerning the likelihood of a regional nuclear war range from highly improbable to apocalyptic. Conservatism in such matters requires that a range of plausible scenarios be considered, given the availability of weapons hardware and the history of regional conflict. In the present analysis, we adopt two potential scenarios: i) a single small nuclear device detonated in a city center by terrorists; and ii) a regional nuclear exchange between two newly minted nuclear weapons states involving a total of 100 low yield (15-kt) detonations. We do not justify these scenarios any further except to note that most citizens and politicians today are aware of the potential disaster of an Israeli-Iranian-Syrian nuclear confrontation, or a Indian-Pakistani territorial confrontation. Moreover, as nuclear weapons knowledge and implementation proliferates, the possible number and combinations of flash points multiplies. The fact that nuclear weapons of the type assumed here have been used in past hostilities substantiates the idea that such scenarios as we propose are executable.

\section{Nuclear arsenals}

Table 1 lists the world's known nuclear arsenals. Five countries were recognized as Nuclear Weapons States in the 1968 Treaty on Non-Proliferation of Nuclear Weapons: France, People's Republic of China, Russia (formerly USSR), United Kingdom and the United States. There are about 30000 nuclear warheads worldwide, $95 \%$ being held by Russia and the U.S. There is enough refined and unrefined nuclear explosive material in the world to construct another 100000 weapons (National Academy of Sciences, 2005). No state has revealed 
Table 1. Nuclear weapons inventories.

\begin{tabular}{ccccccccc}
\hline Country & India & Pakistan & Israel & China & France & Britain & U.S. & Russia \\
\hline Date of analysis & 2003 & 2003 & 2003 & 2003 & 2005 & 2005 & 2005 & 2005 \\
Total \# warheads $^{2}$ & $85(65-110)^{\mathrm{a}}$ & $52(44-62)^{\mathrm{a}}$ & $116(102-130)^{\mathrm{a}}$ & $400^{\mathrm{b}}$ & $350^{\mathrm{c}}$ & $<_{200^{\mathrm{d}}}$ & $5315^{\mathrm{e}}$ & $7200^{\mathrm{f}}$ \\
\# detonated $^{\mathrm{g}}$ & $2-5$ & $2-6$ & & 45 & 210 & 45 & 1030 & 715 \\
\# atmospheric tests $^{\mathrm{g}}$ & & & & 23 & 50 & 21 & 215 & 219 \\
\hline
\end{tabular}

a To compute the numbers of weapons for India, Pakistan and Israel, we used the Pu and HEU estimates of Albright et al. (1997) for 2003. We assumed each weapon contained $5 \mathrm{~kg}$ Pu or $25 \mathrm{~kg}$ of HEU. Parentheses indicate $5 \%$ and $95 \%$ confidence limits on Pu or HEU.

$\mathrm{b}$ Norris and Kristensen (2003). 280 of these are strategic weapons.

c Norris and Kristensen $(2005 \mathrm{c})$.

d Norris and Kristensen (2005e).

e Norris and Kristensen (2005f). 4535 of these warheads are for strategic weapons. There are also 5000 intact warheads in reserve or in inactive stockpiles.

${ }^{\mathrm{f}}$ Norris and Kristensen (2005a). 3814 of these are strategic warheads. Another 9000 intact warheads are in reserve or inactive stockpiles.

g Norris and Arkin (1998).

the precise number of warheads in its stockpile (National Academy of Sciences, 2005). However, the strategic arsenals of Britain, France, Russia, and the U.S. can be reasonably estimated from treaties that verifiably limit the number and capacity of delivery systems. The U.S. and Russia also have significant stockpiles of strategic warheads in reserve, or in storage, beyond those devoted to current strategic delivery systems. The numbers of tactical weapons, including mines, artillery shells, depth charges, and bombs are more uncertain; for example, the Russian tactical stockpile is known only to within 5000 devices (National Academy of Sciences, 2005). Figure 1 plots the trends of nuclear warheads (excluding about 10000 of indeterminate status in Russia for 2002) during the past several decades. As may be seen the numbers of warheads has declined by roughly a factor of 3 in the past two decades.

There are currently three De Facto nuclear weapons states, which have developed weapons outside of the restrictions of the Nuclear Non-Proliferation Treaty: India, Israel, and Pakistan. The arsenals of India, Israel and Pakistan (as well as China) are not well documented. The numbers of warheads they control was determined by several researchers by first estimating the amount of highly enriched uranium (HEU) or of plutonium that could have been produced by each country and allocated to military uses, as opposed to civilian applications. An assumption is then made regarding the amounts of fissionable material needed for each warhead. While all of the available material in military hands may not be assembled into weapons, the numbers in Table 1 assume it has. We omit possible nuclear devices in North Korea, although it is estimated that 10 plutonium weapons in the 10-20 kt range may have been produced (Norris and Kristensen, 2005b).

India and Pakistan conducted nuclear tests in 1998. There are significant differences between the stated yields of the devices in these tests and those estimated from seismic studies (Wallace, 1998). However, the yields of some of the de- vices were similar to the first weapons tested by the U.S., and those dropped on Hiroshima and Nagasaki during WW-II. India claims to have both fusion and fission devices (Norris and Kristensen, 2005d). It has been suggested that India may attempt to build nuclear parity with France, Britain, and China in the next 5-7 years by constructing 300-400 warheads deployed on a triad of delivery systems (missile, aircraft, and submarine) (Norris and Kristensen, 2005d).

In Table 1 we estimate that India has between 65 and 110 weapons, with 85 being most likely. We also estimate that Pakistan has 44-62 weapons with 52 being most likely. Our estimate for India is identical to that of Albright et al. (1997) for India in 2004, because we followed the Albright et al. technique and used their numbers for Pu and HEU. Norris and Kristensen (2005d) estimate India had 40-50 assembled nuclear weapons in 2005. Norris and Kristensen (2006) state that "independent experts" estimate India has 60-105 nuclear warheads, of which 50-60 may be assembled. Norris and Kristensen (2006) state "experts" believe Pakistan has 55-90 weapons with 40-50 assembled. Lavoy and Smith (2003) extrapolated older estimates from Albright et al. (1997) using reactor production rates to determine that India in 2002 might have $40-120$ devices, with a medium guess of 70 , and Pakistan 35-95 with a medium guess of 60 .

Several countries possessed nuclear weapons in the past, but abandoned them. South Africa constructed six devices, which they destroyed, possibly after one nuclear test (Albright et al., 1997). Belarus, Ukraine, and Kazakhstan inherited nuclear weapons with the fall of the Soviet Union, but have transferred them to Russia.

As summarized in Table 2, there are a large number of countries that possess the raw materials needed to construct nuclear weapons, mainly in their civilian nuclear reactor programs. Altogether, 45 nations are identified in Table 2 as having previous nuclear weapons programs, current weapons stockpiles, or the potential to become nuclear states. Thirteen 
Table 2. The dates when various countries halted their nuclear weapons programs; whether they have or once had HEU enrichment facilities, or Pu separation facilities; and the numbers of nuclear weapons that might be constructed from Pu or HEU in their possession at the end of 2003 (Albright et al., 1997). For most countries, the Pu or HEU is in a civilian nuclear reactor program ${ }^{\mathrm{a}}$.

\begin{tabular}{|c|c|c|c|c|}
\hline Country & $\begin{array}{l}\text { Year abandoned } \\
\text { nuclear weapons program }\end{array}$ & $\begin{array}{l}\text { HEU enrichment or } \\
\text { Pu separation facilities }\end{array}$ & $\begin{array}{l}\text { Possible number } \\
\text { of } \mathrm{Pu} \text { weapons, } \\
10 \mathrm{~kg} \text { Pu per weapon }\end{array}$ & $\begin{array}{l}\text { Possible number } \\
\text { of HEU weapons, } \\
25 \mathrm{~kg} \text { per weapon }\end{array}$ \\
\hline \multicolumn{5}{|c|}{ Nuclear Weapons States } \\
\hline China & Active & $\mathrm{HEU}, \mathrm{Pu}$ & 910 & 880 \\
\hline France & Active & $\mathrm{HEU}, \mathrm{Pu}$ & 23610 & $1320-1372$ \\
\hline Russia & Active & HEU, Pu & 27120 & $43520-44120$ \\
\hline United Kingdom & Active & HEU, Pu & $9630-10240$ & 936 \\
\hline United States & Active & HEU, $\mathrm{Pu}$ & 50250 & 28200 \\
\hline \multicolumn{5}{|c|}{ De Facto Nuclear Weapons States } \\
\hline India & Active & $\mathrm{HEU}, \mathrm{Pu}$ & $1390-1490$ & \\
\hline Israel & Active & HEU (?), Pu & 56 & 1 \\
\hline Pakistan & Active & $\mathrm{HEU}, \mathrm{Pu}$ & 84 & 44 \\
\hline North Korea & Active & HEU (?), Pu & 4 & 1 \\
\hline \multicolumn{5}{|c|}{ Non-Nuclear Weapons States } \\
\hline Argentina & $>1990$ & HEU, $\mathrm{Pu}$ & 1100 & \\
\hline Armenia & & & 140 & \\
\hline Australia & $<\mathrm{NPT}^{\mathrm{b}}$ & HEU (?) & & 14 \\
\hline Belarus & Inherited 1990s & & & $10-15$ \\
\hline Belgium & & $\mathrm{Pu}$ & $2350-2450$ & $28-30$ \\
\hline Brazil & $>1990$ & HEU, $\mathrm{Pu}$ & 210 & \\
\hline Bulgaria & & & 850 & \\
\hline Canada & $<\mathrm{NPT}^{\mathrm{b}}$ & $\mathrm{Pu}$ & 13500 & 54 \\
\hline Czech Republic & & & 620 & $3-5$ \\
\hline Egypt & $<\mathrm{NPT}^{\mathrm{b}}$ & & & \\
\hline Finland & & & 1100 & \\
\hline Germany & & $\mathrm{HEU}, \mathrm{Pu}$ & $9300-9600$ & $56-108$ \\
\hline Hungary & & & 750 & $6-10$ \\
\hline Iran & Active & HEU (?) & & \\
\hline Iraq & $1990 \mathrm{~s}$ & & & \\
\hline Italy & & & 650 & $4-8$ \\
\hline Japan & & $\mathrm{HEU}, \mathrm{Pu}$ & $15160-15360$ & 80 \\
\hline Kazakhstan & Inherited 1990s & & 300 & $424-438$ \\
\hline Latvia & & & & 1 \\
\hline Libya & 2003 & & & 1 \\
\hline Lithuania & & & 1000 & \\
\hline Mexico & & & 240 & \\
\hline Netherlands & & HEU & $300-390$ & $29-32$ \\
\hline Poland & & & & 20 \\
\hline Romania & $>1970$ & $\mathrm{Pu}$ & 240 & 1 \\
\hline Slovakia & & & 840 & \\
\hline Slovenia & & & 270 & \\
\hline South Africa & $>1970$, created weapons & HEU & 580 & $24-30$ \\
\hline South Korea & $>1970$ & HEU, Pu & 4400 & \\
\hline Spain & $>1970$ & & 2690 & \\
\hline Sweden & $<\mathrm{NPT}^{\mathrm{b}}$ & & 4180 & \\
\hline Switzerland & $>1970$ & & $1750-2000$ & \\
\hline Taiwan & $>1970$ & $\mathrm{Pu}$ & 2200 & \\
\hline Ukraine & Inherited,1990s & & 4100 & $6-10$ \\
\hline Uzbekistan & & & & 4 \\
\hline Yugoslavia & $>1970$ & & & \\
\hline
\end{tabular}

a Including irradiated and non-irradiated plutonium. Including $\mathrm{HEU}$ at all enrichment levels. Including material owned by the country but not in its territory. We omitted ${ }^{237} \mathrm{~Np}$ and Am which can also be used in weapons.

$\mathrm{b}<$ NPT indicates the program was abandoned at or before signing the Nuclear Non-Proliferation Treaty. 
countries operate plutonium and/or uranium enrichment facilities, including Iran. Obtaining fissionable material, the most difficult step in constructing a weapon, is as straightforward as operating a civilian power reactor system in tandem with a Pu reprocessing facility of appropriate sophistication. All of the necessary technology, equipment, and expertise are available through international markets, which are nominally regulated to prevent proliferation. Nevertheless, as has become apparent over the past decade, nations wishing to build nuclear weapons seem quite capable of doing so despite international restrictions and treaties. In all, 19 countries have had programs to develop nuclear weapons, notably Argentina, Brazil, North Korea, South Korea, and Taiwan (Albright et al., 1997). In 1992 the International Atomic Energy Agency safeguarded less than 1\% of the world's HEU and only about $35 \%$ of the world inventory of Pu (Albright et al., 1997). Today a similarly small fraction is safeguarded.

The possible number of nuclear devices in Table 2 that could be constructed from existing inventories of $\mathrm{Pu}$ and HEU in various countries ranges from one to tens of thousands. We assumed in constructing Table 2, that $10 \mathrm{~kg}$ of $\mathrm{Pu}$ is needed for each warhead, but we did not distinguish $\mathrm{Pu}$ that has been separated from fuel rods from that which has not been separated, and we did not distinguish Pu which is enriched in the favored isotope, ${ }^{239} \mathrm{Pu}$. Weapons constructed by the U.S. and Russia are thought to contain about 3-4 kg of $\mathrm{Pu}$; it has also been suggested that Indian weapons average $5 \mathrm{~kg}$ of Pu. For HEU, $25 \mathrm{~kg}$ per device was assumed to derive Table 2. HEU exists in various states of enrichment of ${ }^{235} \mathrm{U}$, and we do not specifically distinguish weapons-grade material. However, once uranium is enriched to the level of HEU, most of the work needed to achieve weapons grade has already been done, and HEU itself can be used in weapons. There are 8 current states with nuclear weapons, 1 (North Korea) constructing weapons and one (Iran) believed to be actively seeking such devices. Another 32 states possess fissionable material from which weapons could be produced.

Many nuclear weapons are small in size and light in weight and could easily be transported in a car or van. The weapons dropped on Hiroshima and Nagasaki weighed $4040 \mathrm{~kg}$ and $4900 \mathrm{~kg}$ respectively (Gibson, 1996). Subsequent designs have reduced warhead weight-per-yield and size substantially. For example, 300 of the Intercontinental Ballistic Missile warheads in the U.S. arsenal weigh only $\sim 100 \mathrm{~kg}$ each, while the remaining 850 warheads weigh less than $300 \mathrm{~kg}$ each (Gibson, 1996). U.S. submarine-based weapons are similarly light in weight. The U.S. also has about 480 nonstrategic B61 bombs deployed in six European countries, with yields of $100-500 \mathrm{kt}$ and weights of $\sim 300 \mathrm{~kg}$ (Gibson, 1996). The U.S. produced (and retired) 2000 W33 artillery shells, $20 \mathrm{~cm}$ in width and $94 \mathrm{~cm}$ in length weighing $\sim 110 \mathrm{~kg}$ with a yield of 5-10 kt (Gibson, 1996).

The number of nuclear weapons owned by various nations, how many could be successfully delivered, and where they would be delivered are the major uncertainties in the present analysis. As pointed out by the National Academy of Sciences (2005) and Albright et al. (1997) better estimates of the numbers of weapons will only be obtained if nations agree to disclose such information. As discussed below there are many scenarios for how wars might be fought. In this paper we have focused on the delivery of about 50 low yield warheads on urban centers, because that is a rough estimate of the numbers currently existing in the smallest known nuclear arsenals (Table 1). One may argue that the smallest nuclear states currently are not capable of delivering even 50 low yield weapons. However, history shows that once states develop nuclear weapons, they continue to develop more of them, with higher yields. Our idealized study involves about $0.3 \%$ of the world's arsenal by number and only $0.03 \%$ by yield. If regional nuclear arms races continue to develop, the numbers of weapons and their yields can easily exceed the examples we discuss here.

\section{Potential fatalities from a Hiroshima-sized explosion in a major city}

To compute the number of fatalities or casualties from a nuclear detonation, $N$, we use Eq. (1).

$$
N_{\text {fatalities/casualties }}=\int_{0}^{2 \pi} \int_{0}^{R} r P(r, \theta) \alpha(r) d \theta d r
$$

The integral is numerically evaluated over sectors of a city in which the population density, $P$, varies in space. The probability of fatality or casualty, $\alpha$ depends on $\mathrm{r}$, the distance from the detonation point, or "ground zero." $R$ is the maximum distance from ground zero for which the product of $P$ and $\alpha$ yields more than one fatality or casualty in a grid cell. The probabilities for death or injury depend on the types of buildings, the degree of exposure of the population, the time of day, weather, topography, and numerous other factors. However, we assume $\alpha$ only depends on distance from ground zero.

Nuclear weapons cause direct destruction, death and injuries mainly through the effects of prompt energetic gamma and neutron radiation, blast overpressure and winds, and thermal radiance from the fireball (thermal pulse). (The subsequent effects of exposure to radioactive fallout are discussed in Sect. 5). While there have been attempts to estimate damage and casualties associated with nuclear detonations of various yields on the basis of the physical perturbations, there are numerous uncertainties in making such projections. However, for the scenarios considered in this work the explosive yields correspond to those of the Hiroshima and Nagasaki atomic bombs, for which considerable data have been collected documenting deaths and injuries. While the detailed vulnerability of individuals in modern megacities is likely to be significantly different from that at Hiroshima 

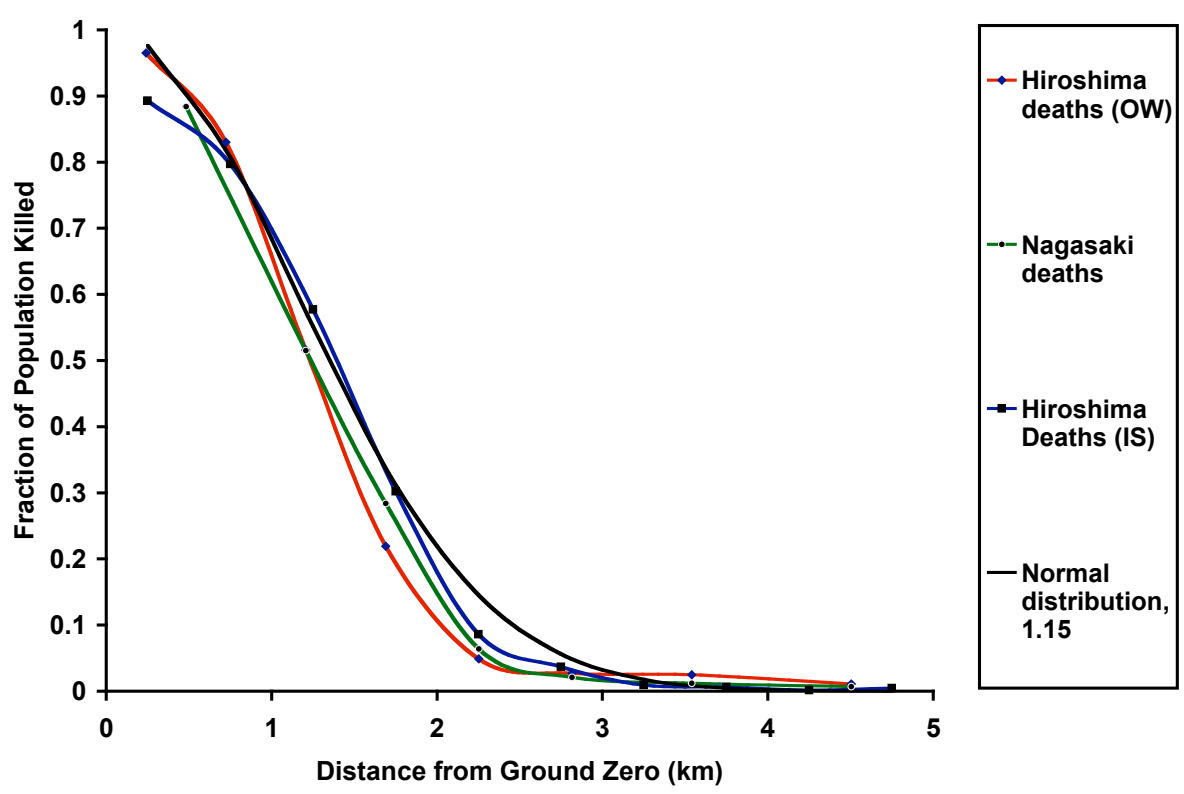

Fig. 2. The fatality curves from Hiroshima ((OW)-Oughertson and Warren, 1956; (IS) Ishikawa and Swain, 1981) and Nagasaki (Oughertson and Warren, 1956), and a normal distribution fit to the Hiroshima data from Ishikawa and Swain (1981) with a standard deviation $\sigma=1.15$.

and Nagasaki, we propose that the overall casualty probabilities should be similar to first-order, particularly in the central zone of heavy destruction where most deaths occur. Accordingly, for the purpose of assessing potential fatalities in a future nuclear conflict or terrorist attack, we will rely on the outcomes of the atomic bombing of Japan in World War II.

Figure 2 shows the Hiroshima and Nagasaki fatality rates from two independent studies (Oughterson and Warren, 1956; Ishikawa and Swain, 1981). The fraction of people killed within Hiroshima and Nagasaki is similar, despite the fact that the energy released by the weapon dropped at $\mathrm{Hi}$ roshima was $15 \pm 3 \mathrm{kt}$, while that at Nagasaki was $21 \pm 2 \mathrm{kt}$. The relatively higher rate of death in Hiroshima is probably due to the geography of the city. Nagasaki has more hills that shadowed areas from the blast and thermal radiation. The firestorm in Hiroshima was also more violent due to the dry conditions and flat terrain, which promoted widespread ignition (Ishikawa and Swain, 1981). Figure 3 illustrates the total casualty probabilities in Hiroshima (Ishikawa and Swain, 1981). Casualties include fatalities and injuries, counting either only serious injuries that are life-threatening in the short run, or all injuries including those minor injuries that are not immediately life-threatening but could become disabling.

We have fit normal distributions to the probability data in Figs. 2 and 3 using a standard form: $\alpha(r)=\exp \left(-r^{2} / 2 \sigma^{2}\right)$. Here, $\alpha$ is the relative probability of fatalities or casualties at a given range, $r$, from ground zero, and $\sigma$ is the effective scaling distance, or distribution width, for the effects of interest. Values of $\sigma$ derived from the data in Figs. 2 and 3 are summarized in Table 3. We used the data from Ishikawa and Swain (1981) to calibrate the casualty distributions because these data refer to the period a year following the explosions when the most serious injuries would have been resolved, and outcomes at each level of effect would be clear. The derived distributions may, nonetheless, represent a conservative estimate of fatalities in the sense that medical attention following the Japanese wartime atomic bombing may have been more accessible than would be the case following an attack on a modern megacity, especially in the developing world. Modern medical treatment might prove effective for at least some of the types injuries that could not be treated during WWII. However, the availability of medical treatment will depend on the numbers of casualties, the damage to the medical infrastructure, and the ability of outside medial experts to enter the combatant countries (e.g. Leaning, 1986).

The Hiroshima and Nagasaki explosions were airbursts. Airbursts do not require sophisticated methods of delivery, a light aircraft, or pressure switch is sufficient. Ground bursts can be delivered by surface vehicles, or from the air. For a ground burst of the same yield, the thermal radiation at a given intensity covers only about $50 \%$ of the area of an airburst, because the fractional conversion of yield to radiant energy changes from 0.35 for an airburst to 0.18 for a ground burst (Glasstone and Dolan, 1977). In addition, the areas affected by overpressure also vary between air and ground bursts. For example, the area within the 10 poundper-square-inch (psi) contour for a ground burst is about $50 \%$ of that for an airburst, while the area within the 2 psi contour for a ground burst is about $38 \%$ of that for an airburst (Glasstone and Dolan, 1977). To adjust the probability curves for computing fatalities and casualties from ground bursts, we divide the appropriate $\sigma$ in Table 3 by a factor of $\sqrt{2}$. This 


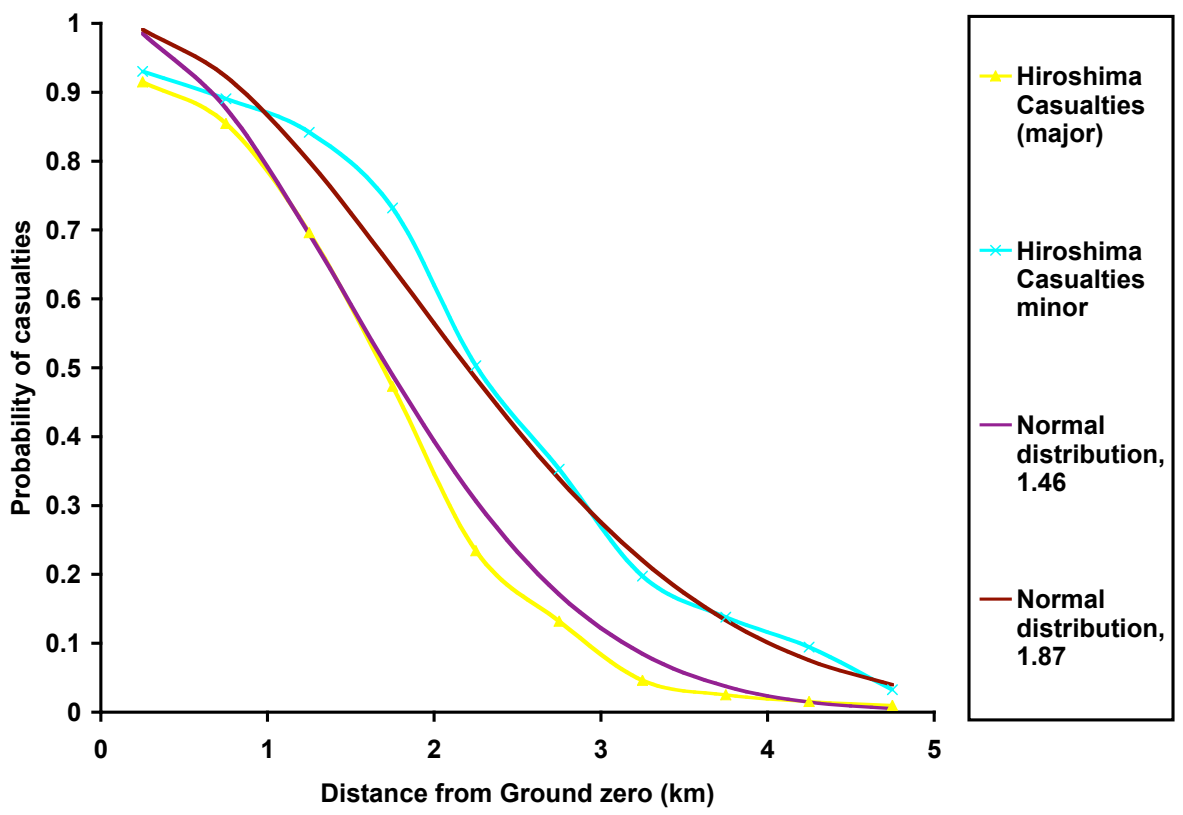

Fig. 3. The casualties in Hiroshima (Ishikawa and Swain, 1981), as well as normal distribution fits to these data with $\sigma=1.46$ and 1.87 . Casualties are defined either as the sum of fatalities plus all major injuries, or fatalities plus all injuries, even relatively minor ones.

Table 3. The characteristic widths, $\sigma$, of the fatality and casualty distributions obtained by fitting data in Figs. 2 and 3.

\begin{tabular}{ll}
\hline Parameter & Width of normal distribution \\
\hline Hiroshima fatalities (Ougherson and Warren, 1956) & 1.0 \\
Hiroshima fatalities (Ishikawa and Swain, 1981) & 1.15 \\
Hiroshima fatalities + serious injuries (Ishikawa and Swain, 1981) & 1.46 \\
Hiroshima fatalities + all injuries (Ishikawa and Swain, 1981) & 1.87 \\
Hiroshima fatalities + injuries from Ishikawa and Swain (1981) & 2.05 \\
\hline
\end{tabular}

effectively reduces the impacted area by $50 \%$ relative to an airburst of the same yield, roughly compensating for the reduced range of both overpressure and thermal radiation effects.

The probability distributions derived above were combined with spatial distributions of population around specific target sites to determine total fatalities and injuries for particular detonation scenarios. We chose target sites by first determining the population within a $3 \mathrm{~km}$ radius about each grid cell in the LandScan for 2003 population data base (LandScan, 2003). The LandScan data base provides the 24-h average ambient population. We then chose the most populated of these regions subject to the constraint that the central cell was separated by at least $6 \mathrm{~km}$ from the center cell of the nearest alternative high population density group of cells. The population data are aggregated into cells that are 30 arcseconds on a side - an area less than $1 \mathrm{~km}^{2}$ at the latitudes of interest. In these calculations, we did not consider the accumulated casualties from multiple bursts in overlap zones within $3 \mathrm{~km}$ of ground zero. In practice, for the most densely populated regions, fatalities from the blast and thermal radiation of a 15-kt explosion do not occur beyond about $5 \mathrm{~km}$ from ground zero, and minor injuries do not occur beyond about $9 \mathrm{~km}$.

Table 4 presents fatalities and Table 5 casualties for airbursts exploded at "optimum" height over the most densely populated, and second most densely populated, regions in a number of countries, as well as for a ground burst in the most densely populated region. These results could represent the consequences of a terrorist attack, or a limited nuclear strike or retaliation. Note that the casualties from the direct effects alone using one weapon can number more than one million even though these scenarios assume low yield weapons. Compared to airbursts, explosions at the ground produce comparable, but somewhat lower, total fatalities - including deaths attributable to radioactive fallout as discussed below. Several previous researchers have investigated casualties in individual cities; for example McKinzie et al. (2001) use an 
Table 4. Potential Fatalities From a Single 15-kt Detonation in a Megacity.

\begin{tabular}{|c|c|c|c|c|c|c|}
\hline Country & $\begin{array}{l}\text { Airburst Total } \\
\text { Fatalities: } \\
\text { Highest Density City }\end{array}$ & $\begin{array}{l}\text { Airburst Total } \\
\text { Fatalities: } \\
\text { Second Highest Density City }\end{array}$ & $\begin{array}{l}\text { Ground Burst Blast/Fire } \\
\text { Fatalities: } \\
\text { Highest Density City }\end{array}$ & $\begin{array}{l}\text { Ground Burst Radiation } \\
\text { Fatalities: } \\
\text { Highest Density City }\end{array}$ & $\begin{array}{l}\text { Estimated Fatalities, } \\
\text { Previous Conflicts }\end{array}$ & $\begin{array}{l}\text { Equivalent Number } \\
\text { of Airbursts }\end{array}$ \\
\hline Argentina & 223000 & 156000 & 111000 & 56000 & $700^{\mathrm{a}}$ & 1 \\
\hline Brazil & 385000 & 266000 & 207000 & 32000 & 0 & 1 \\
\hline China & 760000 & 592000 & 450000 & 74000 & $3320000^{\mathrm{b}}$ & 6 \\
\hline Egypt & 612000 & 601000 & 317000 & 111000 & $8500^{\mathrm{a}}$ & 1 \\
\hline France & 269000 & 198000 & 144000 & 28000 & $592000^{\mathrm{b}}$ & 3 \\
\hline India & 571000 & 469000 & 419000 & 62000 & $3000^{\mathrm{a}}$ & 1 \\
\hline Iran & 287000 & 274000 & 155000 & 38000 & $450000-730000^{\mathrm{a}}$ & $2-3$ \\
\hline Israel & 225000 & 161000 & 132000 & 25000 & $2800^{\mathrm{a}}$ & 1 \\
\hline Japan & 223000 & 206000 & 114000 & 31000 & $2133000^{\mathrm{b}}$ & 14 \\
\hline Pakistan & 503000 & 487000 & 249000 & 103000 & $3-8000^{\mathrm{a}}$ & 1 \\
\hline Russia & 299000 & 237000 & 152000 & 35000 & $17700000^{\mathrm{b}}$ & $>50$ \\
\hline UK & 126000 & 111000 & 76000 & 39000 & $453000^{\mathrm{b}}$ & 5 \\
\hline U.S. & 206000 & 190000 & 114000 & 44000 & $405000^{\mathrm{b}}$ & 3 \\
\hline
\end{tabular}

a (Clodfelter, 1992). In the case of Iran, the 1980-1988 Iran-Iraq war was considered; for Egypt and Israel, the 1973 war; Argentina, the 1982 conflict with the UK; India and Pakistan, the 1971 war.

$\mathrm{b}$ (Ellis, 1993). Russian fatalities are derived from those for the USSR during WW-II.

Table 5. Summary of casualties from one nuclear explosion of $15 \mathrm{kt} \mathrm{yield}^{\mathrm{a}}$.

\begin{tabular}{llll}
\hline Country & $\begin{array}{l}\text { Severe injuries/slight } \\
\text { injuries/total casualties, one air- } \\
\text { burst, highest density city } \\
\text { (thousands) }\end{array}$ & $\begin{array}{l}\text { Severe injuries/slight } \\
\text { injuries/total casualties, one air- } \\
\text { burst, second highest } \\
\text { density location } \\
\text { (thousands) }\end{array}$ & $\begin{array}{l}\text { Severe injuries/slight } \\
\text { injuries/total } \\
\text { casualties, } \\
\text { ground burst, highest density city } \\
\text { (thousands) }\end{array}$ \\
\hline Argentina & $123 / 179 / 526$ & $77 / 102 / 335$ & $70 / 109 / 290$ \\
Brazil & $165 / 197 / 746$ & $80 / 83 / 430$ & $114 / 156 / 477$ \\
China & $265 / 297 / 1,322$ & $166 / 165 / 923$ & $203 / 258 / 911$ \\
Egypt & $317 / 450 / 1,379$ & $264 / 342 / 1,207$ & $184 / 283 / 785$ \\
France & $126 / 166 / 561$ & $92 / 123 / 418$ & $79 / 116 / 339$ \\
India & $249 / 327 / 1,147$ & $212 / 273 / 954$ & $160 / 230 / 709$ \\
Iran & $127 / 157 / 571$ & $134 / 197 / 606$ & $84 / 119 / 358$ \\
Israel & $81 / 91 / 397$ & $65 / 74 / 300$ & $60 / 78 / 271$ \\
Japan & $117 / 163 / 503$ & $117 / 177 / 500$ & $68 / 104 / 287$ \\
Pakistan & $272 / 381 / 1,155$ & $261 / 363 / 1,111$ & $159 / 242 / 651$ \\
Russia & $157 / 229 / 685$ & $100 / 142 / 479$ & $92 / 140 / 384$ \\
UK & $41 / 48 / 214$ & $62 / 85 / 258$ & $33 / 40 / 149$ \\
U.S. & $94 / 131 / 430$ & $77 / 103 / 370$ & $58 / 85 / 257$ \\
\hline
\end{tabular}

a Total casualties include fatalities plus all injuries. For the ground bursts casualties caused by radiation are not considered.

approach similar to ours for Pakistan and India. While a precise comparison is not feasible, they estimate 2.9 million fatalities and 7.7 million casualties if 10 cities in Pakistan and India were attacked with Hiroshima sized weapons. In our scenario we do not attack individual cities, but population concentrations. For our ten highest density regions in India and Pakistan we find 4.3 million fatalities and 8.9 million casualties.

The number of fatalities during WW-II in Hiroshima has been estimated at $140000 \pm 10000$, and in Nagasaki, $70000 \pm 10000$ (Ishikawa and Swain, 1981). Modern megac- ities have higher population densities than Hiroshima and Nagasaki, and consequently would suffer greater fatalities, as indicated in Table 4. Historical wars in most countries, including India, Pakistan, Israel, Egypt, Argentina, and Brazil, have caused fatalities (Table 4 ) of only a few percent of those that could be produced by a single airburst.

There are numerous uncertainties in computing fatalities and casualties. We believe that the uncertainties in our analysis, such as using the casualty probability curves from Hiroshima, and using the LandScan population database, are relatively small. For instance, in Table 4 the average ratio of 
fatalities in the air and ground bursts is 1.85 for a factor of 2 change in $\sigma^{2}$. Since the area within a given damage contour is proportional to $\sigma^{2}$, one would expect the ratio to be 2 if the population density were uniform over the area. The ratio of 1.85 , slightly less than 2 , indicates that the population is concentrated in the center of the area so that slightly less damage occurs as the zone of destruction expands. As noted in Table 3 two estimates of the Hiroshima fatalities give $\sigma^{2}$ values whose ratio is 1.3 . Hence, had we chosen the casualty curve of Oughterson and Warren (1956) instead of Ishikawa and Swain (1981) we would have calculated fatalities that were about 30\% lower than in Table 4. In order to investigate the sensitivity of our results to the population database we also investigated fatalities in China, India, Japan, Pakistan, and the USA using the population database from Columbia University (CIESIN, 2004). This population database is on a coarser grid than LandScan, with a typical area per grid cell near $20 \mathrm{~km}^{2}$ at the latitude of Pakistan. Hence, the population density does not vary over the typical scale of the nuclear damage area. The data we used were for 1995 from CIESIN, while LANDSCAN updates data to remain as current as possible. In this case we found that with the CIESIN database fatalities were $20 \%$ greater for the USA but only $23 \%$ as large for China than with LANDSCAN. As discussed in the next section we also investigated the fatalities from attacks on the 50 most populated regions for several countries. In this case the two databases yield results within $10 \%$ for India and Japan. The CIESIN database yields 30\% higher fatalities for the USA, but only $40 \%$ as high fatalities for China and about $50 \%$ for Pakistan. We believe that the CIESIN database is not on a fine enough scale to be reliable for these calculations. As we discussed above a difference of about $10 \%$ is likely due to not being able to integrate the fatality curves over the population distribution. We expect, however, that the larger differences for China and Pakistan reflect the large increase in urban population that has occurred between the 1995 CIESIN database and the 2003 LandScan database. To summarize, the differences between LandScan and CIESEN are not random, but rather due to lower spatial resolution and older data in the CIESIN database, which is why we chose to use the LANDSCAN data. Likewise we chose the Ishikawa and Swain (1981) fatality curves because they were done at a later time when more data were available.

The greatest uncertainty in our fatality estimates, as noted in the introduction, is likely to lie in the targeting of the weapons, and in the types of weapons used. Table 4 shows that ground bursts are likely to produce about $75 \%$ as many fatalities as air bursts, but, as discussed later, also leave behind lingering radiation. We previously discussed the $33 \%$ fewer fatalities that occur if one targets the 10 largest cities in India and Pakistan rather than the ten most densely populated regions. Based on our discussions of the linear relation of damage area to $\sigma^{2}$, and to the fact that the damage area varies linearly with yield, it follows that the fatalities will be roughly proportional to yield. The yield could vary by a factor of 10 or more from our assumed 15 -kt, depending on the sophistication of the weapons maker. There are numerous other uncertainties related to the use of the weapons. For example, the populations of some urban areas vary greatly between day and night due to commuting patterns. Hence, casualties will depend on the time of day of the attack. The LandScan data base defines a 24-h average population density, which therefore lies between the extreme possibilities. Casualties will also depend upon whether the urban areas have been evacuated in advance of the attack or whether bomb shelters exist. We have assumed there has been no evacuation, or effective use of shelters. Firstly, urgent evacuation of megacities has never been successfully attempted. Moreover, few of these cities have nuclear-capable shelters in any number. While some modern buildings are better designed to survive shock waves, and are less likely to ignite, we have implicitly assumed that all buildings would respond like those in Hiroshima during World War II. Some cities may have complex topography that may provide partial sheltering as in Nagasaki. As discussed in Sect. 4 some targets have several times higher populations densities and will therefore have higher fatalities than others. In this section of the paper we chose examples based on attacks on the most densely populated areas in numerous countries listed in Table 4. The effects of choosing alternative urban targets is discussed in Sect. 4.

\section{Potential direct casualties in a regional war}

Several groups, considering a range of exchange scenarios, estimated the direct casualties in a full-scale nuclear war prior to the collapse of the Soviet Union and the easing of tensions between the larger nuclear powers. Tens of thousands of weapons were available in the 1980s with most in the $100 \mathrm{kt}$ to Mt yield range. Varying assumptions about targeting of the weapons, and the number of weapons used led to casualty estimates differing by more than a factor of ten. Another source of differences between casualty estimates is the scaling of casualty probabilities from low yield weapons, such as the one used in Hiroshima, to high yield weapons. Most researchers use blast damage to scale casualty probabilities. Others have used fire potential, which leads to a greater damage area and generally higher casualty figures by factors of 2.5-4 (Postol, 1986).

At the high end of casualty projections, the "Ambio" study (Middleton, 1982) assumed 14747 detonations (173 in the Southern Hemisphere) totaling $5569 \mathrm{Mt}$. Although, as Table 1 indicates, such a conflict could still be fought today, many of the warheads would need to be taken from storage. The "Ambio" analysis assumed weapons exploded over nearly every city of modest size in the world (most of Africa, South America, and New Zealand were spared). Of the 1300000000 people then living in urban areas of the Northern Hemisphere, it was estimated that 750000000 would die 
immediately, 340000000 would be seriously injured - and of those 200000000 would perish soon there after. Harwell (1984) considered an attack confined to the U.S. involving more than 3000 weapons and $1400 \mathrm{Mt}$ yield, and found that 50000 000-100000000 people might die from blast, thermal radiation, and fires. OTA (1979) summarized several U.S. government studies of a range of scenarios, including a full-scale attack on the U.S. against military and economic targets involving thousands of weapons releasing thousands of megatons of explosive energy. They suggested that casualties, primarily due to blast, would lie in the range of 20000000-160000000 people. The range of casualties was largely due to assumptions about evacuations of urban areas, and use of shelters. They also examined a "counterforce attack," in which military facilities were attacked while U.S. urban centers were not directly targeted. In this case, fatalities, due largely to fallout, were estimated to be 2000000-20000 000 people. Daugherty et al. (1986) pointed out that many strategic targets lie near population centers. They considered a counterforce attack on the U.S. with 3000 warheads and $1340 \mathrm{Mt}$ yield, and deduced that 7000 000-19000 000 deaths might occur immediately from blast and fires in urban areas. Many more fatalities could also be associated with radioactive fallout.

In our computations we have assumed that the densest population centers in each country are targeted. There are many circumstances that could trigger a regional-scale nuclear conflict, and many scenarios for the conduct of the ensuing war. For instance, analysts (Lavoy and Smith, 2003) suggest Pakistan and India could get into a nuclear war because a conventional conflict threatened to overwhelm the strategic conventional forces or command and control structure of either side. Alternatively they might launch a nuclear war to preempt a nuclear attack, real or imagined, by their adversary. Iran and Israel, and numerous other countries, might exchange nuclear weapons for similar reasons in the future. In our analysis we assumed that the densest population centers in each country-usually in megacities-are attacked. Such an urban attack might be conducted to inflict maximum damage. It is likely that military targets would also be attacked. We have not attempted to locate specific military targets, and ignored casualties related to such targets, but note that many military targets are in cities. Hence the "small" wars assumed here are similar in principle, if not in scale, to the strategies for all out nuclear warfare and war fighting embraced by the superpowers in the mid-20th century in the context of "mutually assured destruction".

Below we consider a nuclear war in which 50 weapons of $15 \mathrm{kt}$ yield are detonated on two opposing nations. The total yield in this case is $1.5 \mathrm{Mt}$, roughly $0.1 \%$ or less of the total yields proposed in previous scenarios for a full-scale nuclear war as discussed above. Such a scenario is consistent with the potential arsenals of the smallest recognized nuclear powers, India and Pakistan. One may argue that this scenario is currently implausible because India and Pakistan would need to have their entire arsenals assembled, and a high success rate of delivery to cause 50 nuclear explosions in each territory. However, other nuclear powers have many more weapons and sophisticated delivery systems and could launch such an attack. Moreover, once states begin to assemble nuclear weapons they tend to continue to build their arsenals. For example, India may be moving toward an arsenal comparable to that of China, Britain and France (Norris and Kristensen, 2005d). North Korea has reactors, which if completed and made fully operational, could produce enough fissionable material to produce 50 warheads per year (Norris and Kristensen, 2005b). Whether Pakistan is planning such a reactor is uncertain, but India has recently signed a treaty with the U.S. allowing the continued, and unmonitored, production of fissionable materials. Numerous countries listed in Table 2 have the uranium and/or plutonium to make very large numbers of weapons. Hence we consider an attack involving two countries using 50 low-yield weapons to be within the range of the smallest nuclear powers today, and potentially attainable by many countries in the near future.

Tables 6 and 7 present our estimates of the fatalities and casualties due to targeting $5015-\mathrm{kt}$ weapons on the leading population centers in a number of countries. The total fatalities in Table 6 range from 2600 000-16 700000 . An attack on India, for example, would lead to many more fatalities than a similar attack on Pakistan because of India's greater number of large population centers.

In most of our simulations targets cluster within the megacities located in the combatant countries. For example, Fig. 4, shows the locations of the 28 targets in Japan that fall within the Tokyo-Yokohama region for an attack on Japan using 15-kt yield weapons targeted at the 50 densest population centers. In many countries, half the fatalities occur in a single megacity in our scenario, as summarized in Fig. 5.

Figure 6 shows that fatalities are relatively uniformly spread over the 50 targets in most countries, so that fatalities are not strongly dependent on the details of the choice of targets. For instance, in India and for China, 19 explosions account for roughly half the total airburst fatalities from a 50 weapon attack.

The fatalities in Table 6 for a 50-weapon attack on the United States are comparable to those previously estimated for a limited or counterforce attack involving 3000 weapons and $1300 \mathrm{Mt}$ (OTA, 1979; Daugherty et al., 1986). Scaled against total weapon yield, the fatalities per kiloton are 100 times greater in the small weapon scenario, even when full scale urban targeting has been considered in past scenarios (Harwell, 1984). The high fatality rate of low yield weapons is not due to any non-linear phenomena. While the use of thousands of high-yield weapons would certainly lead to more casualties than might occur in a small attack or exchange with low-yield weapons, the number of casualties is not reduced in proportion to the total yield because of inefficient use of the huge arsenals of high yield weapons. For example, even today Russia and the USA maintain much larger 
Table 6. Fatality estimates for 50 15-kt detonations in urban zones.

\begin{tabular}{llll}
\hline Country & $\begin{array}{l}\text { Blast and Fire Fatalities: } \\
\text { Airbursts }\end{array}$ & $\begin{array}{l}\text { Blast and Fire Fatalities: } \\
\text { Ground Bursts }\end{array}$ & $\begin{array}{l}\text { Radiation Fatalities: } \\
\text { Ground Bursts }\end{array}$ \\
\hline Argentina & 4337000 & 2394000 & 810000 \\
Brazil & 7962000 & 4370000 & 1834000 \\
China & 16716000 & 9306000 & 2554000 \\
Egypt & 7834000 & 4384000 & 1656000 \\
France & 3509000 & 1879000 & 923000 \\
India & 12424000 & 6494000 & 2539000 \\
Iran & 7431000 & 4231000 & 1371000 \\
Israel & 2594000 & 1538000 & 323000 \\
Japan & 5890000 & 3023000 & 1766000 \\
Pakistan & 9171000 & 5112000 & 1525000 \\
Russia & 6273000 & 3543000 & 7299000 \\
UK & 2891000 & 1565000 & 872000 \\
U.S. & 4056000 & 2203000 & \\
\hline
\end{tabular}

Table 7. Summary of casualties from 50 weapons with $15 \mathrm{kt}$ yield ${ }^{\mathrm{a}}$.

\begin{tabular}{lll}
\hline Country & $\begin{array}{l}\text { Severe injuries/slight injuries/total casualties, } \\
\text { 50 airburst weapons (thousands ) }\end{array}$ & $\begin{array}{l}\text { Severe injuries/slight injuries/total casualties, } \\
50 \text { ground burst weapons (thousands ) }\end{array}$ \\
\hline Argentina & $1846 / 2233 / 8415$ & $1242 / 1736 / 5371$ \\
Brazil & $3522 / 4445 / 15929$ & $2283 / 3267 / 9920$ \\
China & $6955 / 8560 / 32230$ & $4755 / 6550 / 20611$ \\
Egypt & $3146 / 3623 / 14604$ & $2219 / 3011 / 9614$ \\
France & $1570 / 1907 / 6986$ & $1037 / 1472 / 4388$ \\
India & $6069 / 7853 / 26347$ & $3731 / 5552 / 15776$ \\
Iran & $2890 / 3316 / 13637$ & $2064 / 2772 / 9067$ \\
Israel & $868 / 918 / 4380$ & $693 / 863 / 3094$ \\
Japan & $2991 / 3953 / 12834$ & $1797 / 2716 / 7536$ \\
Pakistan & $3830 / 4562 / 17563$ & $2597 / 3613 / 11321$ \\
Russia & $2468 / 2897 / 11638$ & $1762 / 2362 / 7667$ \\
UK & $1287 / 1621 / 5799$ & $845 / 1199 / 3608$ \\
U.S. & $1825 / 2305 / 8186$ & $1176 / 1691 / 5070$ \\
\hline
\end{tabular}

a Total casualties include fatalities plus all injuries. For the ground bursts radiation caused casualties are not considered.

arsenals than are needed to strike all significant military targets as well as every moderate to large city in the adversary country. Many weapons are aimed at the same target, or aimed at missile silos or submarines in unpopulated regions. For high-yield weapons in the Mt range, much of the area inside the destruction zone would be sparsely populated- even in large cities- as the population density decreases rapidly toward the perimeter. Therefore, based on the present results, relatively small numbers of low yield weapons targeted at densely populated urban centers may lead to similar casualties as in a full-scale counterforce war.

Table 6 also shows that a regional exchange between India and Pakistan, in which each side used 50 weapons, could lead to more than 21 million fatalities, which is equivalent to about half of the global fatalities in WW-II. Only a small number of weapons are needed to produce the same fatalities in a given country as occurred among that country's citizens during WW-II, or in other major historical wars. For example, three weapons of 15-kt yield exploding in the U.S. could lead to more U.S. fatalities than occurred during all of WWII.

The uncertainties discussed for individual targets in Sect. 3 also apply to a regional scale war. Generally we believe the greatest uncertainties have to do with targeting issues, such as the time of day of the attack and whether cities have been evacuated before an attack. For a regional scale war the numbers and yields of weapons that are actually exploded, and the targets chosen is a significant uncertainty. As illustrated in Fig. 6 the numbers of fatalities varies almost linearly with the numbers of weapons used near the 50th target. In general 


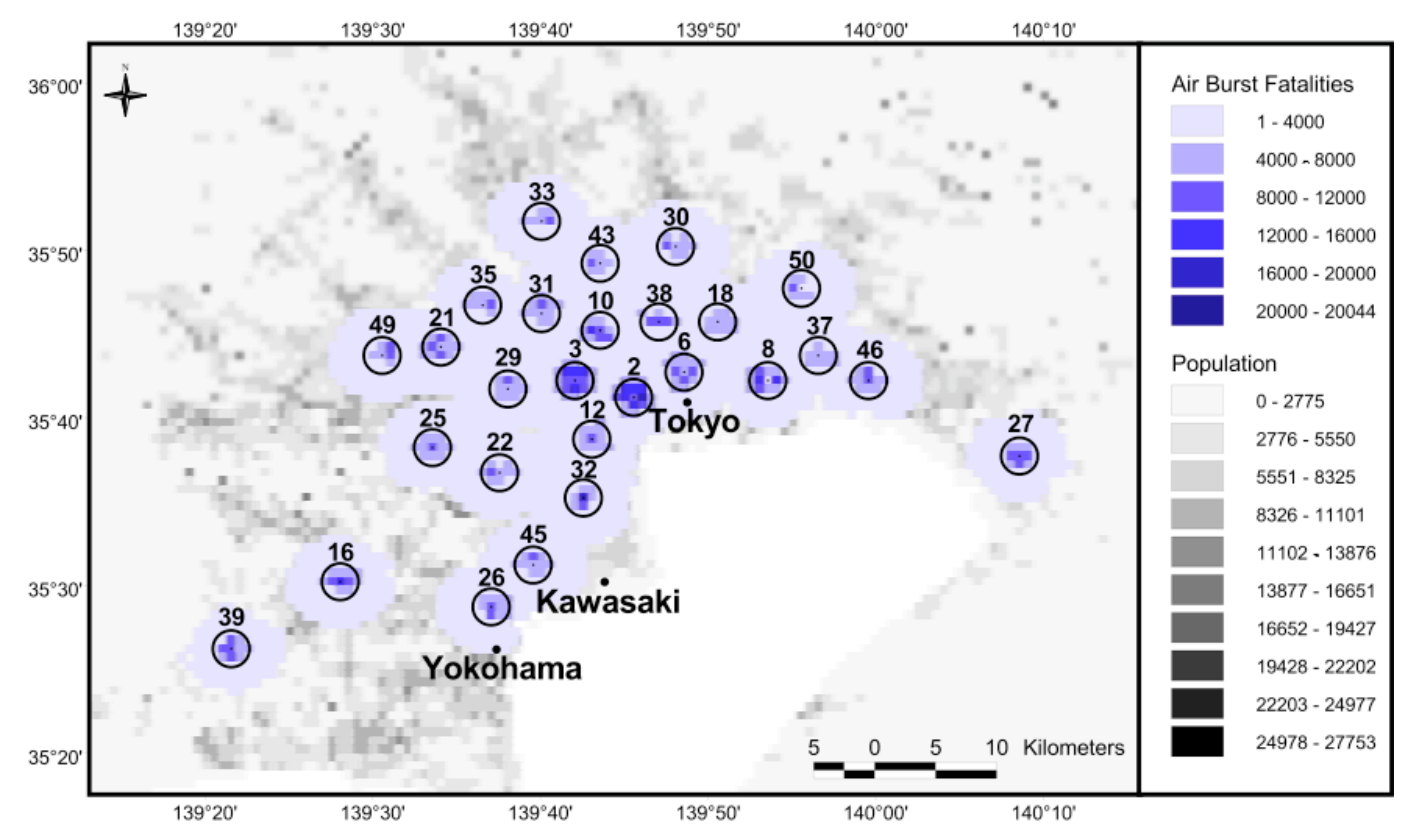

Fig. 4. Targeted areas in the Tokyo/Yokohama, Japanese megacity complex are identified for the scenario used in the present analysis. The axes are latitude and longitude. Of the 50 hypothetical Japanese targets, 28 are located in this urban complex. Circles of 2-km radius define the areas around target points where fires are likely. The blue shades indicate fatalities per grid cell from an airburst. No fatalities occur in the gray regions, which are shaded according to population per grid cell.

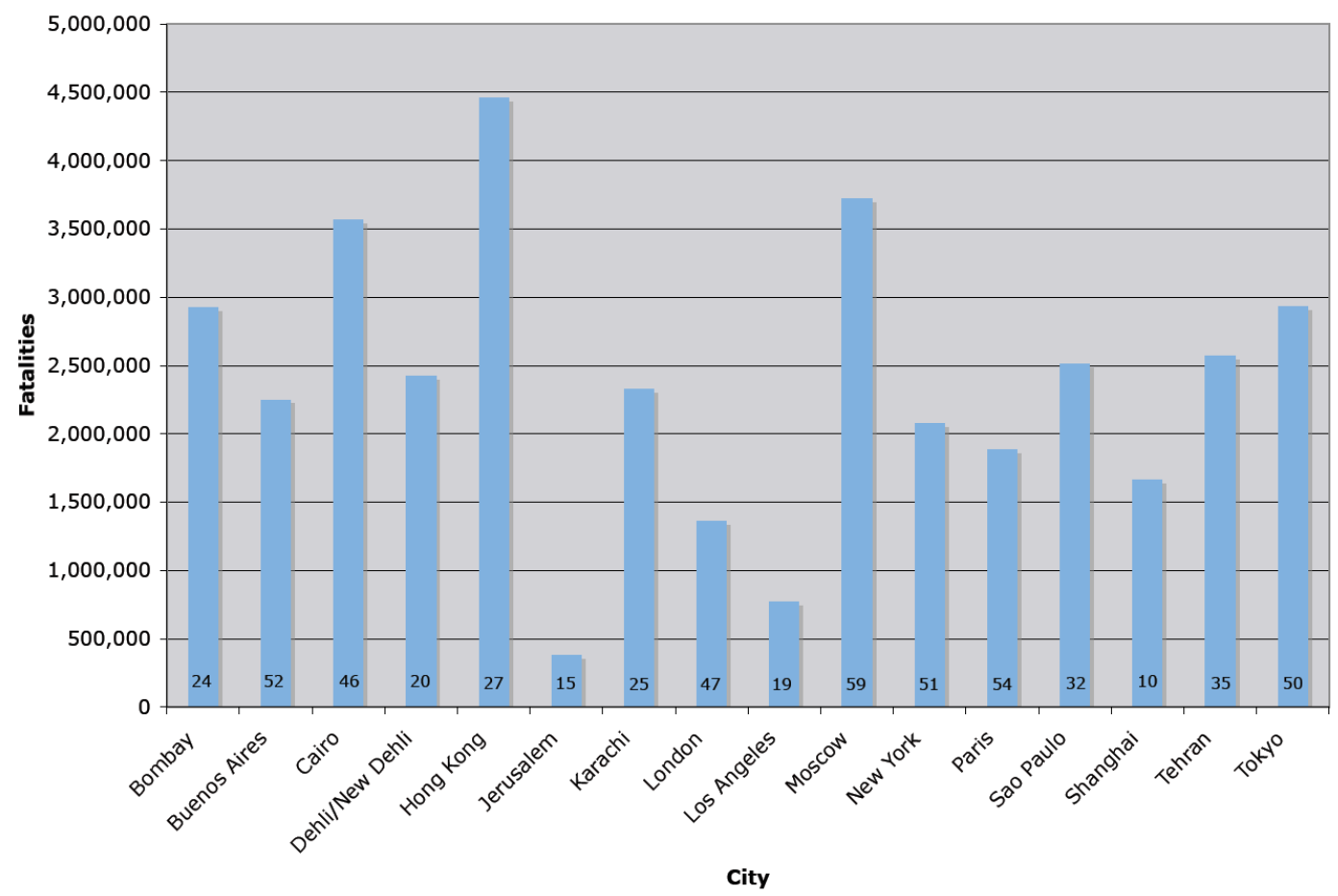

Fig. 5. Total fatalities predicted for specific megacities in several countries. The numbers on the bars represent the percentage of the country's fatalities occurring in the megacity. Buenos Aires, Cairo, London, Moscow, New York, Paris, and Tokyo account for 46-59\% of their national fatalities for the scenario treated. 


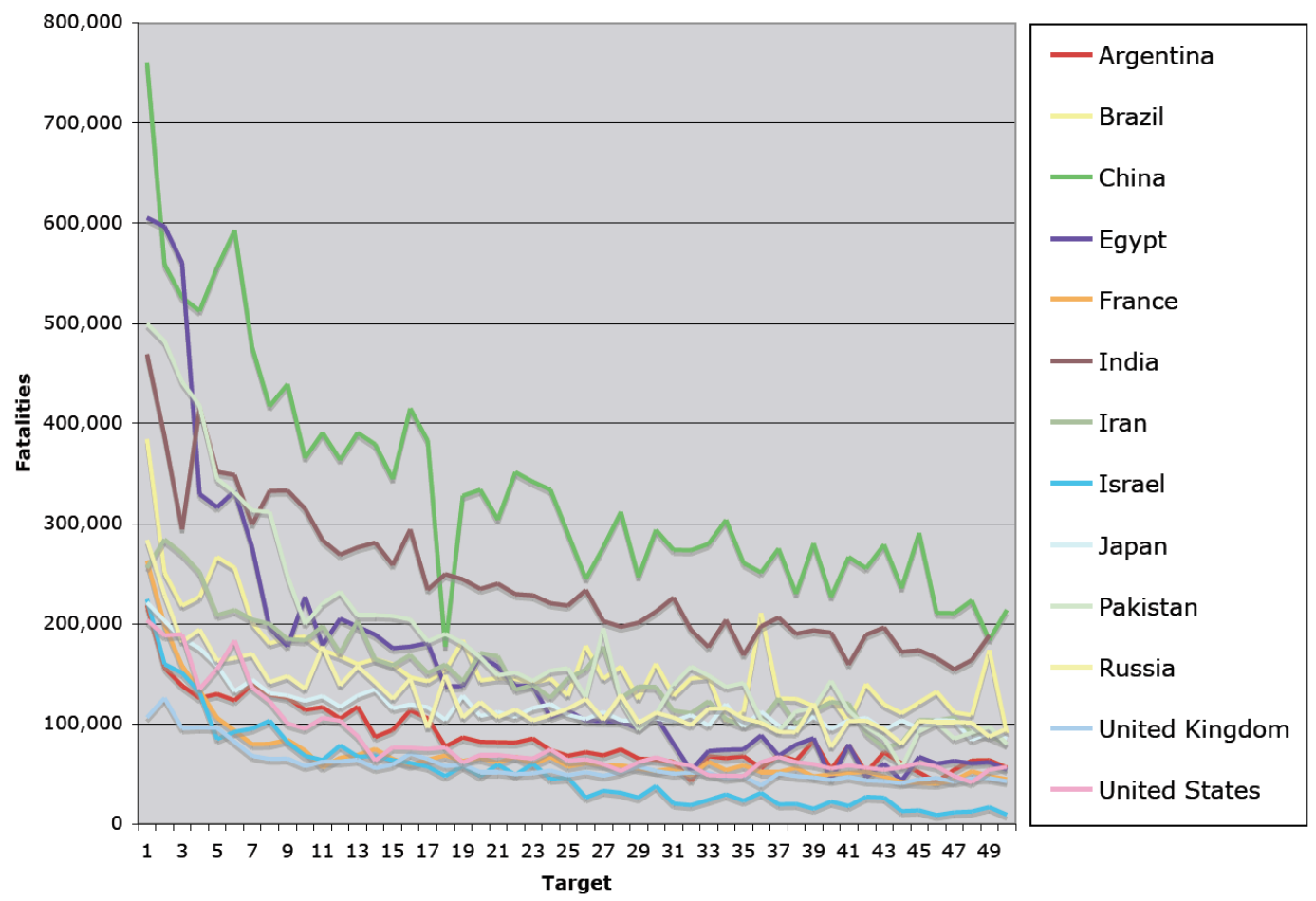

Fig. 6. Potential fatalities caused by airbursts of 15-kt yield on each of 50 targets in the countries listed. These curves are well fit with simple analytic formulas. For example for China, Fatalities=703 442-124 303Ln(target number), for Pakistan Fatalities=528 435-11 6181Ln(target number), for the U.S. Fatalities=208 940-43 044Ln(target number).

these curves are well fit over the entire range with a relationship in which the number of fatalities is proportional to the natural $\log$ of the target number. Explicit equations are given in the Fig. 6 caption for several examples.

\section{Radioactive fallout}

In previous calculations for a full-scale nuclear war, radioactive fallout was a significant source of fatalities. For example, Harwell (1984) predicted about $25 \%$ of the United States land area would be exposed to a long-term fatal dose of radiation, resulting in 50000000 to 70000000 fatalities in addition to those due to direct effects such as blast. The radioactivity is primarily associated with surface explosions, which are typically used to attack "hardened" or buried military targets, such as missile silos. However, surface bursts generally cause fewer blast or fire fatalities. Harwell (1984), for example, found that when all of the urban explosions were surface bursts, the total number of fatalities was actually reduced by 10000000 .

There have been numerous studies of early radioactive fallout from nuclear surface bursts, and potential exposure to energetic radiation, especially gamma rays, emitted by the residual radionuclides. Early fallout consists of the dustborne radioactive byproducts deposited on the ground during the first day or so after a nuclear surface explosion. Surface bursts raise large amounts of dust, which carries most of the short-lived radioactive isotopes released in fission detonations. Subsequent fallout patterns depend on the dust particle size distribution, height of the stabilized debris cloud, and local weather, among other factors. Airbursts generally are assumed to produce no early fallout unless it is raining, as discussed below. In general, most of the lethal fallout from a small surface burst (e.g., $15 \mathrm{kt}$ ) is deposited within one to two hours of detonation, and within several tens of kilometers of ground zero. Moreover, the threat of fallout exposure within $2-3 \mathrm{~km}$ of such a burst is secondary to the hazards associated with prompt radiation (emitted at the time of detonation), blast, and thermal radiation. Since these latter effects are directly accounted for by the casualty curves discussed above, we will not be concerned here with detailed modeling of the fallout closer than one or two kilometers to ground zero (although the model discussed below will roughly account for this fallout).

Given the complexity of the fallout problem, and sensitivity to parameters such as wind speed, rainfall and dust particle size that cannot be determined in advance, we utilize the simplified fallout model documented by Glasstone and Dolan (1977) to compute areas subject to given exposure levels downwind of a surface contact burst. This model was based upon experience from nuclear weapons tests. 

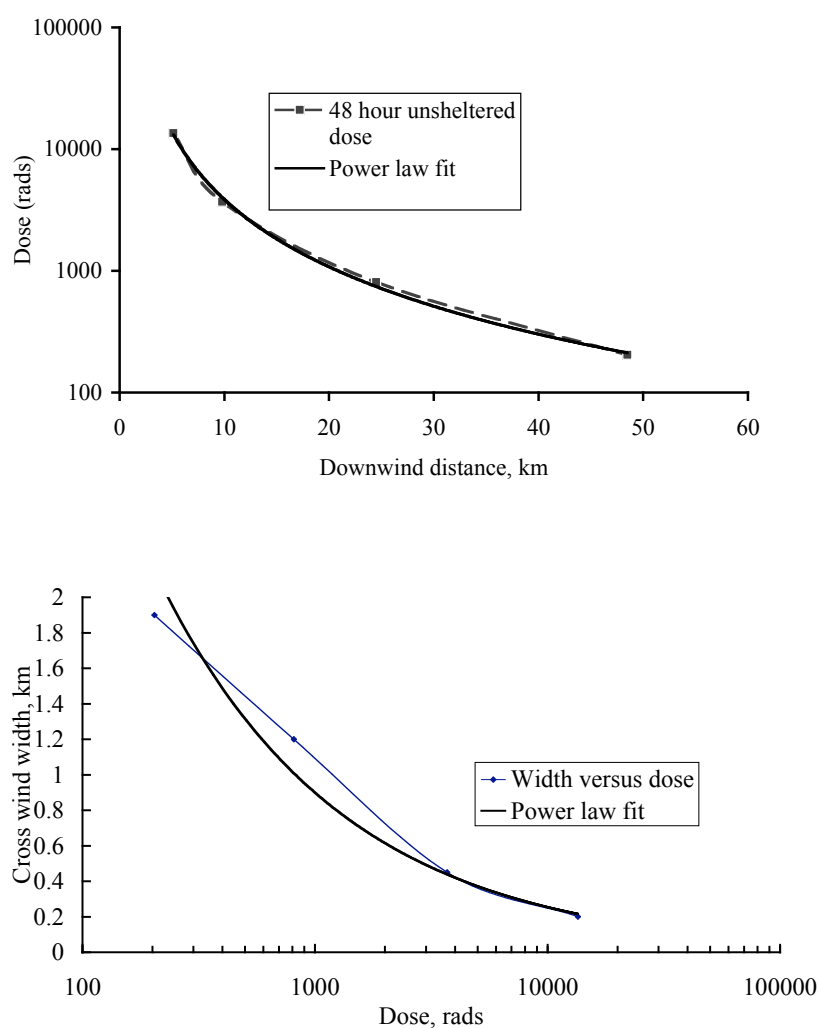

Fig. 7. (top): Potential unsheltered 48-h whole-body gamma ray dose downwind of a 15-kt ground burst based on the simplified fallout model documented in Table 9.93 and Fig. 9.26 in Glasstone and Dolan (1977). These values do not include reductions for surface roughness, or for purposeful sheltering. The 48-h period of exposure is assumed to begin when fallout reaches the distance indicated, although roughly $80-90 \%$ of the total dose is received within the first $24 \mathrm{~h}$. For an assumed $24 \mathrm{~km} / \mathrm{h}$ steady wind with minimal vertical shear, the initial times range from about $10 \mathrm{~min}$ to $2 \mathrm{~h}$ after detonation. (bottom): Ground zero width of a given dose contour based on the same model (for example, the ground zero cross-sectional width of the area contour in which the 48-h unsheltered dose is at least 1000 rad is about $1 \mathrm{~km}$ ); the maximum width occurs downwind of the burst at a distance determined by the wind speed at ground zero but varies little from the ground zero width. For each set of data, a power law fit is shown.

In applying the model, Table 9.93 and Fig. 9.26 of Glasstone and Dolan (1977) are used to characterize the dose rate, and integrated dose, downwind of a 15-kt fission ground burst. The results are summarized in Fig. 7 in terms of the potential external gamma ray dose that would be received after $48 \mathrm{~h}$ of continuous exposure over a perfectly flat surface as a function of distance from the detonation. The derived doses must be corrected for terrain and sheltering as discussed below. Typically, $50-60 \%$ of the total fission radioactivity produced by a surface burst is deposited as early fallout, and this factor is incorporated in the model (Glasstone and Dolan, 1977; Shapiro et al., 1986).
The model (Glasstone and Dolan, 1977) assumes there is a steady $24-\mathrm{km} / \mathrm{h}$ wind with minimal wind shear. We take the wind to blow directly toward the east, as prevailing westerlies although in reality the winds could blow in any direction, and in some countries we consider prevail toward the west. The delay in fallout exposure associated with transport from the detonation point is accounted for by estimating the arrival time using the derived distance and known wind speed. The fallout radiation dose rate decays in proportion to $\mathrm{t}^{-1.2}$, with time, t, measured in appropriate units (Glasstone and Dolan, 1977). Given an arrival time, and an exposure interval of 2 days, a dose rate "multiplying factor" can be obtained by time integration of the dose rate. The actual 48-h dose is then the product of the reference time dose rate and the multiplying factor.

Figure 7a shows the potential maximum 48-h whole-body dose as a function of downwind distance from a 15-kt burst obtained from the Glasstone and Dolan (1977) model. Figure $7 \mathrm{~b}$ gives the ground zero crosswind width of the contour delimiting that dose. The data in Figs. 7a and $b$ have been fit with power law functions for convenience in our analysis. The 48-h unsheltered exposure at each distance directly downwind of a surface detonation can be reasonably estimated using the relation,

$D=266000 / L^{1.838}$

where $\mathrm{D}$ is the integrated dose in $\mathrm{rad}$, and $\mathrm{L}$ is the distance from ground zero in $\mathrm{km}$. Note that Eq. (2) can be inverted to give the maximum downwind extent for any specific dose, D. The simplified model of Glasstone and Dolan (1977) also predicts that, for a 15-kt fission explosion, the width of the dose contour is nearly independent of the range from the detonation point. Hence, we further assume that for a particular dose, the contour width, $\mathrm{W}(\mathrm{km})$, remains constant over the range given by Eq. (2). The fit in Fig. $7 \mathrm{~b}$ gives this width as,

$W=40 / D^{0.5486}$.

Based on the assumptions stated above, the derived exposure footprints for early fallout from a 15-kt surface burst consist of rectangular areas, $\mathrm{L} \times \mathrm{W}$, defined through Eqs. (2) and (3), that extend to the east of the burst point.

For the scenarios considered here, the population grid cells are generally comparable to or larger in width than the exposure contours that fall within the lethal range. Moreover, in multiple burst scenarios, the dose contours often overlap. In cases where we must estimate the affected population in subgrid areas, we assume a uniform population density within affected grid cells, so that the exposed population is directly proportional to the fractional area. We also sum exposures from overlapping explosion contours. Figure 8a, for example, illustrates the 48-h exposures predicted for unsheltered individuals in the Tokyo-Yokohama megacity complex corresponding to a 50-weapon attack on Japan. Note that there are many areas where a number of fallout patterns overlap in 
such an attack, and the total exposure consists of the additive component exposures.

Following Daugherty et al. (1986), we assume that 50\% of the population will have a sheltering factor of 3 , and $50 \%$ a sheltering factor of 10 . Hence, the true exposure, $\mathrm{D}^{\prime}$ is, $\mathrm{D}^{\prime}=\mathrm{D} / 3$ or $\mathrm{D} / 10$. The response of a population to a given acute (48-h) dose of whole-body radiation is uncertain. The dose that is lethal to $50 \%$ of the exposed individuals has been estimated in various studies to lie between 220 and $450 \mathrm{rad}$ (Daugherty et al., 1986). We use $450 \mathrm{rad}$ in the present analysis. We further assume, based on Daugherty et al. (1986), that the fatality curve is linear with dose, and that the fatality rate would be $100 \%$ at $600 \mathrm{rad}$, and $0 \%$ at $300 \mathrm{rad}$. Then the fraction of fatalities for a given acute exposure (above $300 \mathrm{rad})$ is:

$\alpha_{\text {radiation fatality }}=\left(\mathrm{D}^{\prime}-300\right) / 300 ; \quad 0<\alpha<1$

The doses used in Eq. (4) are those modified for the effects of sheltering. Hence, the unsheltered dose rate that represents the threshold for lethality (from fallout alone) is $900 \mathrm{rad}$ for $50 \%$ of the affected population, and 3000 rad for the other $50 \%$.

Given these parameters the fallout from a 15-kt ground burst could be lethal to all the survivors of blast and fire within a zone extending roughly $8 \mathrm{~km}$ downwind, and $0.35 \mathrm{~km}$ wide. At distances greater than about $22 \mathrm{~km}$ from ground zero, there would be few fallout fatalities, although radiation sickness would affect a substantial number of individuals exposed to radiation at 100-300 rad (with effects potentially exacerbated by other stresses, and the absence of an organized medical response). Between the epicenter of the explosion and $22 \mathrm{~km}$, there would be zones of varying widths in which a fraction of the population suffers lethal exposure. For example, the dark purple areas illustrated in Fig. $8 \mathrm{~b}$ for the Tokyo-Yokohama megacity attack scenario would be subject to numerous early fallout casualties.

There has been limited consideration in the literature of the effects of rainfall on radioactive fallout (Glasstone and Dolan, 1977). This is due in part to the fact that most high-yield weapons rise and stabilize in the atmosphere well above the region where rainfall develops. However, the stabilized height of a 15-kt airburst debris cloud is around $6000 \mathrm{~m}$, which is within the middle troposphere (Glasstone and Dolan, 1977). The top of the Nagasaki mushroom cloud was estimated to be $4000-5000 \mathrm{~m}$, with a base near 1200 $1300 \mathrm{~m}$ (Ishikawa and Swain, 1981). It follows that a $15-\mathrm{kt}$ yield device initially deposits its radioactivity in the middle to lower troposphere. In this case, rapid removal is likely if the atmosphere is unstable and rainfall is occurring in the region. For this reason, atmospheric nuclear tests were detonated in remote locations, in part to avoid local rainfall effects (Glasstone and Dolan, 1977). Precipitation might scavenge radioactive debris from the plume of an airburst at the same rate as dry sedimentation removes radioactivity from a ground-burst cloud. Moreover, rainfall could potentially
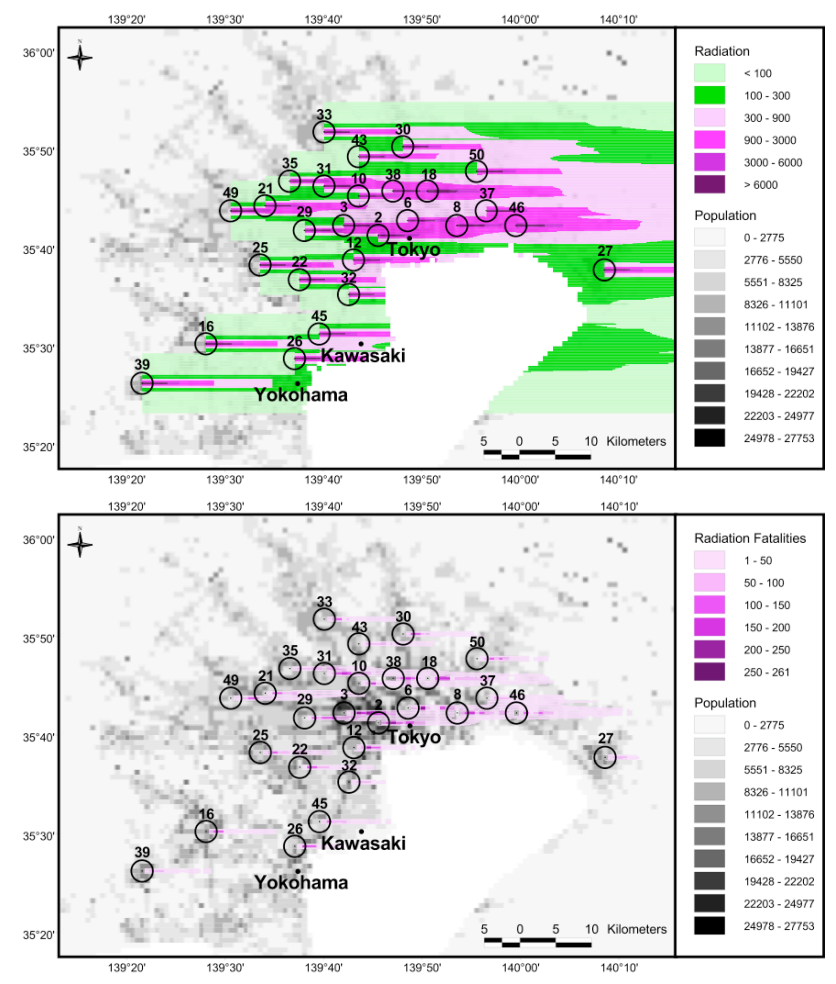

Fig. 8. (top): Map of estimated radiation doses (rads) for unsheltered individuals in the Tokyo-Yokohama megacity. The axes refer to latitude and longitude. The black circles locate $\sim 2-\mathrm{km}$ radius zones of destruction by fire around each target. (bottom): Locations where most of the fatalities due to early fallout would occur (the darker purple contours indicating very high fatality rates per grid cell, as discussed in the text). The background shading depicts the population per grid cell, with the darker grey representing the highest density. Both the radiation cells and the radiation fatality grid cells are $1 / 25$ the area of a population grid cell.

deposit twice as much radioactivity locally following an airburst as a ground burst in dry weather, since in the latter case only about half the radioactivity is in the form of particles large enough to be deposited as early fallout. As discussed later the mass fires likely to occur after a nuclear explosion are capable of generating pyro-convection and possible associated rainfall. However, it takes several hours after the explosion for these clouds to develop, by which time the nuclear debris cloud will have blown away. Hence preexisting natural rainfall in the area of the explosion is the source of greatest concern for short-term radioactivity from an airburst.

For the scenarios considered here, Tables 4 and 6 provide estimates of the fatalities due to the early fallout from single and multiple ground bursts without rainfall. While the radiation casualties are substantial in the cases treated, the total of blast, fire and radiation fatalities for ground bursts are found to be somewhat lower in general than the direct fatalities of an airburst of equivalent yield. Rainfall has the potential to increase radiation fatalities significantly. 
Delayed, as opposed to early, radioactive fallout generally occurs within the first day or two after a nuclear explosion, and far downwind of ground zero. Global-scale fallout is associated mainly with high yield weapons whose radioactivity is deposited initially in the stratosphere, and is then slowly removed over the globe. Intermediate fallout is associated with radioactive debris that remains trapped in the troposphere, and which is deposited regionally. About 500 nuclear weapons were exploded in the atmosphere worldwide prior to the nuclear test ban treaty, with a total yield expended of more than $400 \mathrm{Mt}$. Of greater relevance here, 100 airburst weapons with an average yield of $10 \mathrm{kt}$ were detonated over the Nevada test site (NTS). About 61 of these devices had a high enough yield to produce measurable radioactivity beyond the NTS (Bouville et al., 2002). The tests were deliberately conducted in locally dry conditions, so that the debris would remain aloft as long as possible, decaying and dispersing before returning to the surface. Occasionally hot spots, such as in northern New York State, occurred as a result of rainfall scavenging. In the U.S., the overall cumulative external population exposure associated with the 100 small weapons exploded at the NTS was comparable to that connected with the global fallout from the $400 \mathrm{Mt}$ of large weapon tests (Bouville et al., 2002). The smaller bursts were more effective per unit fission yield because the shorterlived fission radioisotopes were much more rapidly deposited (Bouville et al., 2002). The radioactive debris from the larger weapons was injected into the stratosphere, where it decayed significantly before reaching the ground. In counties downwind of the NTS, average exposures of the order of $300 \mathrm{mrad}$ have been estimated (Bouville et al., 2002), which is comparable to the average annual radiation dose from natural radioactivity.

In a regional-scale nuclear war, radiation doses over large areas would most likely exceed doses experienced during the NTS series. For one thing, the detonations would occur simultaneously rather than over a decade of time, and would be deposited in the same restricted area. Moreover, local rainfall is more probable in the regions considered here, and could significantly exacerbate the local and regional deposition of radioactivity. The fallout simulation illustrated in Fig. 8a shows, for example, that most of the greater Tokyo area, and extending more than $100 \mathrm{~km}$ downwind, is subject to unprotected 48 -h doses of 50 to $200 \mathrm{rad}$. In the same zone, the cumulative dose between 1 day and six months would be roughly half the values for 48 - $\mathrm{h}$ - still a very substantial exposure equivalent to perhaps a thousand times background. Under such circumstances, it is likely that only a small fraction of the population would remain within the urban complex, being limited mainly to those directly engaged in disaster relief and civil defense activities.

While regional and global fallout are not likely to cause substantial fatalities following a war between states with small arsenals (Glasstone and Dolan, 1977), it is much more likely that large urban areas around target points would be permanently abandoned, especially following ground burstsor airbursts under rainy conditions. A nuclear explosion releases many short and long-lived radionuclides, amounting to roughly $30000 \mathrm{MCi}$ per kiloton of fission yield at one minute after detonation (Glasstone and Dolan, 1977). Thus, the evacuation of large regions would be necessary immediately after a nearby surface burst. However, the deposition of long-lived radioisotopes, as occurred after the Chernobyl nuclear reactor accident in April 1986, would make early recovery and re-colonization untenable in contaminated zones. Chernobyl released about $2.5 \mathrm{MCi}$ of ${ }^{137} \mathrm{Cs}$ and $0.27 \mathrm{MCi}$ of ${ }^{90} \mathrm{Sr}$, (Nuclear Energy Agency, 2002). In contrast, $50 \mathrm{nu}-$ clear explosions of $15 \mathrm{kt}$ fission yield would be expected to release about $0.2 \mathrm{MCi}$ of ${ }^{137} \mathrm{Cs}$ and $0.14 \mathrm{MCi}$ of ${ }^{90} \mathrm{Sr}$, both with half-lives close to $30 \mathrm{yr}$. Notably, the local deposition following Chernobyl was attenuated owing to the small particle sizes released by the reactor, and most of the activity dissipated over long distances, whereas early radioactive fallout would concentrate activity locally. Nevertheless, shortly after the Chernobyl accident, a region of $2800 \mathrm{~km}^{2}$ was evacuated, which exceeds the total area affected by blast in the nuclear scenarios considered here. Several other radioactive "hotspots" were located within a few hundred kilometers of Chernobyl where rainfall deposition occurred. In total, $3100 \mathrm{~km}^{2}$ was contaminated by ${ }^{137} \mathrm{Cs}$ at levels above $40 \mathrm{Ci} / \mathrm{km}^{2}, 7000 \mathrm{~km}^{2}$ at levels between 16 and $40 \mathrm{Ci} / \mathrm{km}^{2}$, and $103000 \mathrm{~km}^{2}$ between 1 and $5 \mathrm{Ci} / \mathrm{km}^{2}(\mathrm{Nu}-$ clear Energy Agency, 2002). Eventually the Soviet Union adopted a ground-contamination upper-limit of $40 \mathrm{Ci} / \mathrm{km}^{2}$ of ${ }^{137} \mathrm{Cs}$ for permanent resettlement of population, and 15 $40 \mathrm{Ci} / \mathrm{km}^{2}$ for temporary relocation. In this latter zone, consumption of contaminated food remains strictly controlled; the 193000 people living here in 1995 received an annual dose below 500 mrads (where 300 mrads is the average annual dose received from natural background radioactivity) (Nuclear Energy Agency, 2002). Sixteen years after the accident, $4000 \mathrm{~km}^{2}$ of agricultural land remained abandoned, including the entire area within $30 \mathrm{~km}$ of the reactor. Following the attack scenarios considered here, slightly smaller total areas might be abandoned or strictly controlled, but these areas would be within, or adjacent to, current megacity centers. Accordingly, the population and economic assets affected would dwarf the Chernobyl values.

The uncertainty in computing the radioactivity deposited from the explosion of 50 weapons with $15 \mathrm{kt}$ yield lies in variables such as the local wind speed, and whether it was raining during the explosion. However, the greatest uncertainty is due to targeting issues, such as whether ground bursts are used. Fatalities due to fallout exposure depend on how well sheltered the population is, and how quickly it can evacuate the region. 


\section{Smoke emissions}

During the early 1980s, numerous investigations of smoke emissions from burning cities suggested that significant global-scale climate changes might occur following a nuclear war (Alexandrov and Stenchikov, 1983; Turco et al., 1983, 1990; Pittock et al., 1985). Climate changes could impact non-combatant countries worldwide, and potentially lead to significant global casualties. At that time, significant climate effects were expected from 100 high yield weapons being used on 100 cities, but given the large numbers of weapons then available such a scenario did not seem likely. Here we estimate the smoke generated from 100 low yield weapons being used on 100 targets, many of which may be co-located in a single megacity. Robock et al. (2007) evaluate the climate changes that may occur from this estimated smoke release.

It is not practical to employ currently limited information on land-use in hundreds of urban complexes around the world to determine accurately the local and regional distributions of combustible materials that could be ignited by nuclear bursts. To estimate fuel loadings for the present work, we make a basic assumption that within urban zones there is a direct relationship between the quantity of fuel available and the local population density. Contributing to the fuel load would be dwellings, offices, industries and infrastructure such as schools, transport and fuel depots, shopping malls, and so on. Given the relationship between fuel loading and population density we can use population density data as a surrogate for fuel loading data. In the next section we discuss the relationship between fuel loading and population density, as well as other parameters needed to determine the smoke emissions. Next we discuss the altitude to which the smoke plumes might rise. We then apply this technique to determine smoke emissions from attacks on a number of cities and countries.

\subsection{Estimating fuel loading and smoke emissions}

We estimate the mass of carbonaceous smoke (often referred to as elemental carbon, or soot) emitted by fires ignited by a single detonation in a specific location as follows:

$M_{e}=\sum_{j=1}^{J} P_{j} A_{j}\left\{M_{f}\left(\sum_{i=1, n} F_{i} Q_{i} S_{i} C_{i}\right) R\right\}$

Here, $M_{e}$ is the total mass of the potential soot emission. The outer sum, $j$, is over all grid cells in the region affected by the explosion and subject to fire ignition. $P_{j}$ is the population density (people $/ \mathrm{km}^{2}$ ) within the grid cell $j$, which can be determined using an appropriate population database for the area (LandScan, 2003). $A_{j}$ is the area of the grid cell, or the fractional area impacted by fire. In summing, we include a total of $J$ cells arranged symmetrically around ground zero such that the total area burned following a 15-kt explosion is
$13 \mathrm{~km}^{2}$, equivalent to that consumed at Hiroshima (Glasstone and Dolan, 1977).

The term within brackets does not vary with location around ground zero in this treatment. The key parameter, $M_{f}$, represents the baseline per capita mass of fuel of all types estimated for the nation and locale of interest. In practice, we establish a baseline for the developed world circa 1980, and scale the results for other circumstances (see below). In the past, two techniques have been employed to determine the baseline fuel burden. Turco et al. (1990) analyzed the total quantities of various types of flammable materials that were produced and utilized annually in developed nations. Then, with an estimate of the relevant residence time (in years) for each material, the total quantities of fuel were determined. The most extensive information available at the time related to the 1980s. The total amount of all fuels in the developed world at the time was estimated to be $11.4 \pm 3.6 \times 10^{3} \mathrm{Tg}$ (teragram, or $10^{12} \mathrm{~g}=10^{6}$ metric ton), where the range represented the minimum and maximum likely values. Dividing by the total population of the developed world in 1980 - about $1.1 \times 10^{9}$ people - a mean value, $M_{f}=1.1 \pm 0.4 \times 10^{7} \mathrm{~g} /$ person, was derived.

An alternative approach to find $\mathbf{M}_{f}$ was taken by Small (1989) and Bush et al. (1991). They surveyed land-use in a cross-section of U.S. cites, and incorporated data on the amounts of combustible materials in typical structures, including various types of residences, industries and businesses. Their analysis yielded a total quantity of fuel in U.S. urban "target zones" of about $1322 \mathrm{Tg}$. Specifically, the targeted areas were delimited using an attack scenario that involved hundreds of megaton-sized weapons. However, Small (1989) did not quantify the number of individuals affected within targeted cities, stating more generally that onehalf of the entire urban-suburban area of the U.S. lay within the target zones. Using the entire urban population of the U.S. in 1980 (152 million), a lower limit of the fuel per capita would therefore be $8.7 \times 10^{6} \mathrm{~g} /$ person. Assuming that onehalf of the population resided in target zones at the time, the inferred per capita fuel loading would be $1.7 \times 10^{7} \mathrm{~g} /$ person These results roughly bracket the range derived by Turco et al. (1990). Accordingly, a baseline per capita fuel burden, $M_{f}$, of $1.1 \times 10^{7} \mathrm{~g} /$ person is adopted here. Later, we return to the question of modern fuel loadings, and combustibles in other parts of the world.

In Eq. (5), $F_{i}$ is a fraction that divides the total combustible mass loading into different types, or categories, $i$ (refer to Tables 8 and 9). $Q_{i}$ is the fraction of a fuel type that is assumed to burn following nuclear ignition, and $S_{i}$ is the mean elemental carbon emission factor for that fuel type (Tables 8 and 9). To adjust the estimated smoke emissions for national differences in fuel characteristics, a parameter, $C_{i}$, is also specified as the ratio of the fuel type per person in the city in question to the fuel type per person in the developed world in 1980. Finally, to account for smoke removal in "black rains" induced by firestorms, the average fraction of emitted 
Table 8. Fuel parameters for developed world circa 1980 (Turco et al., 1990).

\begin{tabular}{lllll}
\hline Material & Fuel Mass, $\mathrm{Tg}^{\mathrm{a}}$ & $\begin{array}{l}\text { Fraction of mass } \\
\text { in a given category, } \mathrm{F}\end{array}$ & $\begin{array}{l}\text { Elemental carbon } \\
\text { emission factor, } \mathrm{S}^{\mathrm{b}}\end{array}$ & $\mathrm{F}^{*} \mathrm{R} * \mathrm{~S} * \mathrm{C}^{*} \mathrm{Q}^{c}$ \\
\hline $\begin{array}{l}\text { Wood/lumber } \\
\begin{array}{l}\text { Primary and secondary } \\
\text { petroleum products }\end{array}\end{array}$ & $9450 \pm 3150$ & 0.83 & $0.01(0.002-0.02)$ & 0.0066 \\
$\begin{array}{l}\text { Plastics and polymers } \\
\text { Asphalt roofing }\end{array}$ & $430 \pm 30$ & 0.10 & $0.06(0.03-0.10)$ & 0.0048 \\
\hline
\end{tabular}

\footnotetext{
a Mass in the developed world circa 1980, mid-value \pm extremes.

$\mathrm{b}$ Typical value, range in parentheses.

${ }^{\mathrm{c}} \mathrm{C}, \mathrm{Q}$ assumed to be unity, $\mathrm{R}=0.8$.
}

Table 9. Fuel parameters for U.S. circa 1980 (Small, 1989).

\begin{tabular}{lllll}
\hline Material & Fuel Mass, Tg & $\begin{array}{l}\text { Fraction of mass } \\
\text { in a given category, } \mathrm{F}\end{array}$ & $\begin{array}{l}\text { Smoke emission } \\
\text { factor, } \mathrm{S}\end{array}$ & $\mathrm{F} * \mathrm{R} * \mathrm{~S} * \mathrm{C}^{*} \mathrm{Q}^{\mathrm{a}}$ \\
\hline Wood & 592 & 0.45 & 0.009 & 0.0032 \\
Paper & 71 & 0.05 & 0.005 & 0.0002 \\
Plastics/Rubber & 136 & 0.10 & 0.071 & 0.0057 \\
Hydrocarbons & 278 & 0.21 & 0.037 & 0.0062 \\
Cloth & 58 & 0.04 & 0.017 & 0.0005 \\
Food (dry ) & 13 & 0.01 & 0.013 & 0.0001 \\
Asphalt & 42 & 0.03 & 0.121 & 0.0029 \\
Urban Open & 132 & 0.10 & 0.012 & 0.001 \\
\hline
\end{tabular}

a Assuming $\mathrm{R}=0.8, \mathrm{C}$ and $\mathrm{Q}=1$.

elemental carbon that is not scavenged in fire-induced convective columns is specified by the parameter, $R$, which is assigned a baseline value of 0.8 (see below).

Assuming for the moment that $C$ and $Q$ are unity, the value of the bracketed term in Eq. (5) - based on the data in Table 8 - is $0.016 \mathrm{~g}$ (soot) $/ \mathrm{g}$ (fuel) (Turco et al., 1990). Alternatively, using the data in Table 9, the value is $0.020 \mathrm{~g}$ (smoke) $/ \mathrm{g}$ (fuel) (Small, 1989). An important difference between these estimates is the fraction of fuel in the category of wood and wood products. A more subtle difference is that Turco et al. (1990) estimate the mass of soot generated by fires, while Small (1989) gives the total amount of smoke, of which soot is a partial component. Comparing specific absorptivities, or absorption cross-sections per unit mass, in $\mathrm{m}^{2} / \mathrm{g}$ (smoke), we find that Turco et al. (1990) used $7 \mathrm{~m}^{2} / \mathrm{g}$ (soot) while Small (1989) assumed $4.4 \mathrm{~m}^{2} / \mathrm{g}$ (smoke). These numbers are better normalized by converting specific absorptivity to the absorption coefficient per unit mass of fuel burned (that is, by combining the emission factor and specific absorptivity), which yields a value of $1.1 \times 10^{-1} \mathrm{~m}^{2} / \mathrm{g}$ (fuel) for Turco et al. (1990), and $8.6 \times 10^{-2} \mathrm{~m}^{2} / \mathrm{g}$ (fuel) for Small (1989). These two values are in very reasonable agreement. In subsequent paragraphs, we discuss alternative values for $M_{f}$ and $C$.
To scale fuel loading from population density, we employ a linear relationship that is represented by the solid line in Fig. 9. This relationship corresponds to the baseline fuel mass per person, $M_{f}=1.1 \times 10^{7} \mathrm{~g} /$ person, being distributed over an area of $1 \mathrm{~km}^{2}\left(10^{10} \mathrm{~cm}^{2}\right)$, yielding a slope of $0.0011 \mathrm{~g} / \mathrm{cm}^{2}$ per person $/ \mathrm{km}^{2}$. Figure 9 also compares this baseline model with several other estimates of fuel burdens relative to population density. Bush et al. (1991) studied specific area-averaged fuel loadings in 6 regions of the U.S. based on urban land-use patterns, assigning fuel loadings according to standard land-use categories. Bush et al. (1991) also provided data on the urban population density in each of these areas. We assumed that these urban population densities applied to the roughly $50 \%$ smaller urban areas they used to determine fuel loadings. Their results are indicated by the yellow symbols in Fig. 9. After calibrating against population, we carried out a linear regression for the fuel loading versus population density data points. The regression yielded a zero-population fuel loading of about $0.8 \mathrm{~g} / \mathrm{cm}^{2}$, which is roughly consistent with the background urban and residential vegetation fuels assumed by Bush et al. (1991). Because of this mean background fuel component, the average fuel loadings derived by Bush et al. (1991) are higher (by about 40-60\%) at the lowest 


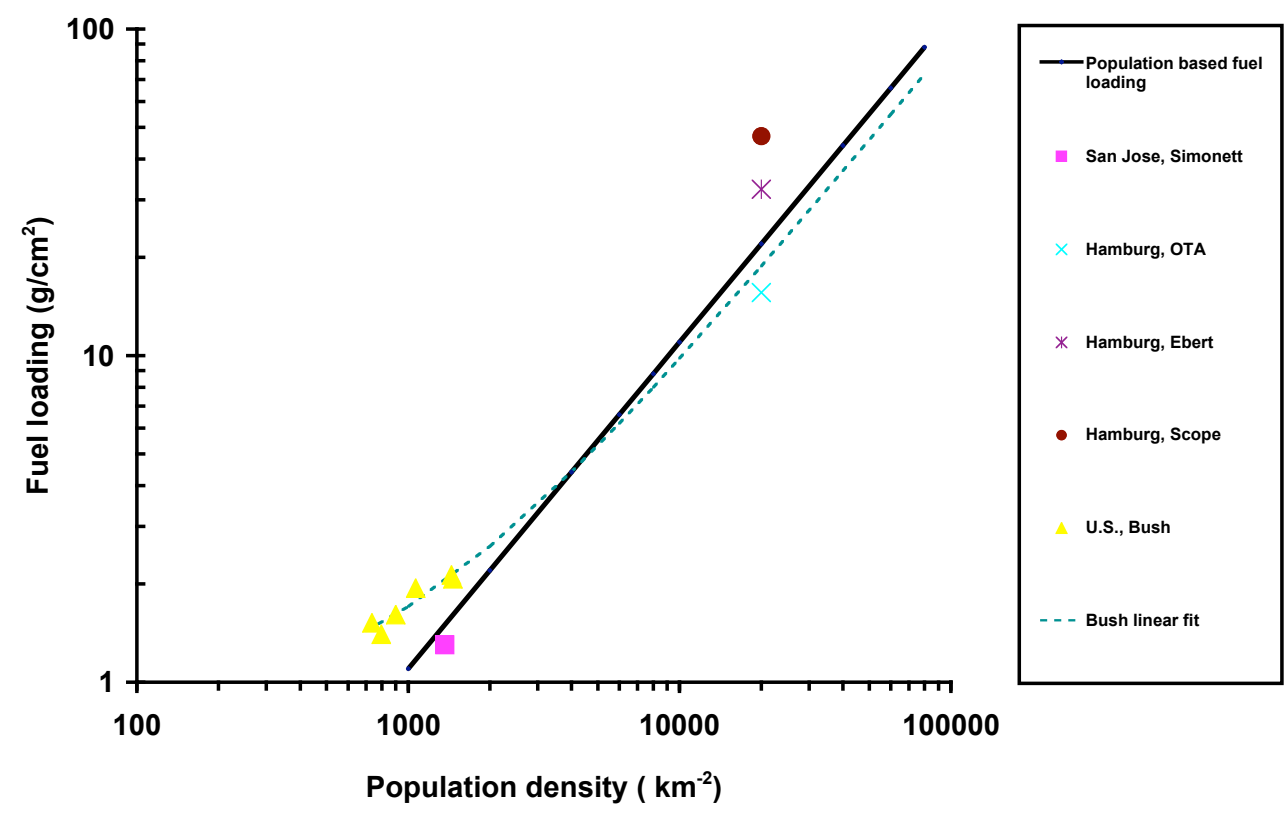

Fig. 9. Information relating areal fuel loading, $F L$, to population density, $P$, is summarized. Data points are based on land-use studies for a number of cities: San Jose, Simonett et al. (1998); Hamburg, OTA (1979); Hamburg, Ebert (1963); Hamburg, Pittock et al. (1985); U.S., Bush et al. (1991). The solid black line corresponds to a linear relationship, $F L \propto P$, or $\Delta \ln F L=\Delta \ln P$, with no background (zero population) contribution to the fuel loading. The dashed curve is an extrapolation of a linear regression derived using data published by Bush et al. (1991); in this case, a background fuel loading associated with urban/rural vegetation was included, which leads to the curvature seen at low fuel loadings.

population densities than the baseline model in Fig. 9. Even so, background vegetation has been ignored in the present analysis in favor of the linear model in Fig. 9. Also shown as a dashed line in Fig. 9 is the extrapolated regression corresponding to the data of Bush et al. (1991), which exhibits curvature at low population densities owing to the background fuel contribution. Significantly, the two fuel loading models extrapolate to very similar values (within $\pm 10 \%$ ) at the higher population densities typical of megacity centers.

For the cases considered by Bush et al. (1991) the mean fuel loadings are relatively low. This can be explained in large part by the fact that Bush et al. (1991) sought to estimate the average fuel loadings that would apply to large yield nuclear weapon detonations over typical, moderatesized U.S. cities, such as Nashville, Tennessee. The footprint of a large weapon encompasses areas far removed from a city center. Hence, on an area-weighted basis, the average fuel loading is likely to be dominated by low values in uninhabited areas around cities, and in residential areas. Similarly, low average population densities would be predicted for target zones associated with high-yield detonations. For example, a 150-kt explosion is capable of igniting an area of $100 \mathrm{~km}^{2}$, which would likely include extensive suburban tracts with low population densities, especially in smaller U.S. cities. While both the mean population density and fuel loading will be biased toward lower values in such cases, the average per capita fuel loading might actually be higher, even without background vegetation, because of the larger square footage associated with residential property. Importantly, when Bush et al. (1991) considered higher density housing districts, predicted fuel loadings were much greater, reaching $9 \mathrm{~g} / \mathrm{cm}^{2}$ in one area of Nashville, for example. This points to the fact that smaller detonations aimed at urban centers should be expected to ignite much higher fuel densities on average than larger yield weapons.

Simonett et al. (1998) analyzed components of the fuel load for San Jose, California. They documented the numbers and types of buildings, and used literature-derived fuel loads for each building type to deduce an average fuel loading of $0.94 \mathrm{~g} / \mathrm{cm}^{2}$ within the city boundaries. The analysis omitted various types of fuels, such as stored petroleum and asphalt in roofing, but estimated that the total fuel load might be $1.34 \mathrm{~g} / \mathrm{cm}^{2}$. Using the 1980 San Jose population of 629246 , and a city area of $440 \mathrm{~km}^{2}$, we obtain a population density of 1370 people $/ \mathrm{km}^{2}$ at the time. The average San Jose fuel loading then falls slightly below the baseline curve in Fig. 9.

Several investigators have determined fuel loads for the portions of Hamburg that experienced firestorms during World War II (Fig. 9). The population density in the burned sections of Hamburg was roughly 20000 people $/ \mathrm{km}^{2}$ (Lucas et al., 1990). Ebert (1963) cites fuel estimates by German fire engineers of $32 \mathrm{~g} / \mathrm{cm}^{2}$ of wood in one area of the city center. The SCOPE assessment (Pittock et al., 1985) cites the fuel loading in Hamburg as $47 \mathrm{~g} / \mathrm{cm}^{2}$, while OTA (1979) 
gives $16 \mathrm{~g} / \mathrm{cm}^{2}$, although neither source is clear on the origins of these values. Schubert (1969) carefully investigated the wood loading in two sections of Hamburg with areas of $0.37 \mathrm{~km}^{2}$ and $0.45 \mathrm{~km}^{2}$, finding values of 16 and $12 \mathrm{~g} / \mathrm{cm}^{2}$, respectively. Peczkis (1988) described Dresden's city center in WW-II as being dominated by 5 -story residences covering a significant fraction of the land area; combustible loadings for such buildings were used to estimate an average fuel burden of $22 \mathrm{~g} / \mathrm{cm}^{2}$. This value is likely to be low since it omits the large amounts of coal stored in the city. A population density was not given.

Similar fuel studies based on land use have not been carried out for the dense inner regions of modern cities. Three types of characteristic American cities circa 1980 were hypothesized by Larsen and Small (1982), leading to fuel burden estimates within the inner 2-km-radius urban cores of 23, 41 , and $63 \mathrm{~g} / \mathrm{cm}^{2}$. In the annular region $2-6 \mathrm{~km}$ from the city centers, the corresponding fuel densities were estimated as 7 , 11 , and $18 \mathrm{~g} / \mathrm{cm}^{2}$, respectively. By contrast, the average fuel load for 50 high population density U.S. urban targets that we derive below using population density is $12 \mathrm{~g} / \mathrm{cm}^{2}$ (Sect. 6.3). These results provide support for the idea that high average fuel densities are associated with nuclear detonation scenarios in which small bursts are aimed at population centers.

The fuel loading per person in the developed world may be greater than that in the developing world, so that the values of $C$ in Eq. (5) may be less than unity. We have found little direct work on fuel loading in countries such as Iran, India and Pakistan. Tall buildings in megacities are not likely to be composed of wood. For example consider Tehran, a modern megacity with a population near 10 million. Tehran has large museums, art centers, palaces and a modern subway system. About $66 \%$ of the buildings are unreinforced masonry (which poses a great earthquake hazard), $27 \%$ are steel construction, and $4 \%$ reinforced concrete (EMI, 2006). The masonry buildings contain little wood in their construction (Maheri, 2005). Similar structures in the U.S. include the World Trade Center Buildings. These are estimated to have contained a fuel loading, per floor, of 1.4 to $1.9 \mathrm{~g} / \mathrm{cm}^{2}$ but the average fuel loading could have been as large as $4.6 \mathrm{~g} / \mathrm{cm}^{2}$ since it was an office building with possibly lots of paper (Rehm et al., 2002). Kumar and Rao (2005) measured fuel loads in Indian office buildings and found an average value corresponding to $1.9 \mathrm{~g} / \mathrm{cm}^{2}$, per floor, which is very similar to values from Britain. Hence what data we have suggest fuel loads in the office buildings in the developing world are similar to those in the developed world, and that the fuel is in building contents as opposed to building structures.

While we have found no specific detailed analysis of fuels in megacities in developing countries, a variety of relevant indirect data available for large urban areas worldwide has been considered to assess the possible variance in $C$. Table 10, for example, compares vehicle ownership per capita, and solid waste created per person, in a variety of megacities (Decker et al., 2000). It is plausible that vehicle usage is re- lated to the quantity of petroleum stored and used in cities. Excluding Los Angeles, these data indicate that megacities in the developing world have on average about 0.38 times as many vehicles as megacities in the developed world, with considerable overlap in specific cases. Similarly, solid waste generation may correlate with the abundances of paper, cardboard, plastics, and other combustible materials, including certain foodstuffs, that are available in urban zones. Cities in the developing world generate roughly half the solid waste per capita as cities in the developed world, suggesting that, on this basis the fuel loading may be correspondingly lower.

Using country-level data to derive fuel burdens per capita may underestimate fuels in cities because urban populations are likely to have more wealth, property, and infrastructure resources than rural populations. This is especially true in the developing world, where the fraction of total population in urban areas is $\sim 40-60 \%$ as compared to $70-80 \%$ in the developed world (as of 2000; Table 11), while urban growth in the developing world is much faster. As a crude measure of relative national economic activity and wealth, carbon dioxide emissions per capita (Marland et al., 2005) can be compared for different regions of the world (Table 11). Adopting an average emission of 2 metric ton-Carbon/person for the "developed" world, and assuming that fuel availability is proportional to carbon emission, we estimate that relative fuel per capita, or the factor $C$, could range from 0.10 to 0.75 in the developing countries listed in Table 11, with an average value of 0.33 . Since $\mathrm{CO}_{2}$ emissions are dominated by fossil fuel consumption, however, this probably represents a significant underestimate of the relative total quantities of combustibles in cities. Further, the more rural nature of populations in developing nations also biases such an estimate of $C$ toward lower values.

Another potential measure of fuel loading, given in Table 12 , is human appropriation of net primary productivity (HANPP) (Imhoff, 2004). This quantity represents the average amount of food, wood, paper and fiber consumed per person. It includes, mainly, cellulosic materials that dominate the fuel mass in the developed world (Tables 8, 9). As pointed out by Imhoff (2004), the ratio of HANPP between the industrialized countries and the developing nations is about 0.56 . This value is comparable to other measures of the parameter, $C$.

Considering the data in Tables 10-12 discussed above, we conclude that the parameter, $C$ - the ratio of the average fuel loading per capita for urban dwellers in the developing world to that in the developed world - may currently lie in the vicinity of $\sim 0.5$. We also note that the more plausible proxies for combustible burdens indicate values of $C$ larger than 0.5 .

A secondary issue concerning the value of $C$ is whether the fuel loading distribution in Tables 8 and 9, or the mass of fuel per person, $M_{f}$, has changed significantly since 1980 (the basis year for the present analysis). The population of the developed world increased by about $12 \%$ between 1980 and 2000. At the same time, the carbon dioxide emitted 
Table 10. Data from cities related to fuel loads (Decker et al., 2000).

\begin{tabular}{lllll}
\hline City & $\begin{array}{l}\text { Population } \\
\text { Millions (1995) }\end{array}$ & $\begin{array}{l}\text { Vehicles } \\
\text { per person }\end{array}$ & $\begin{array}{l}\text { Solid waste } \\
(\mathrm{kg} / \text { day/person })\end{array}$ & $\begin{array}{l}\text { C vehicles/C } \\
\text { solid waste }^{\mathrm{b}}\end{array}$ \\
\hline $\begin{array}{l}\text { Developed World } \\
\text { London }\end{array}$ & 7.3 & & & \\
Los Angeles & 12.4 & 0.370 & $3.4 /$ \\
Moscow & 9.2 & 0.645 & $0.2^{\mathrm{a}}$ & $4.1 / 1.64$ \\
New York & 16.3 & 0.072 & 0.5 & $0.46 / 0.25$ \\
Osaka & 10.6 & 0.069 & $1.6^{\mathrm{a}}$ & $0.7 / 0.82$ \\
Tokyo & 26.8 & 0.164 & 2.5 & $0.4 /$ \\
Average Developed World & & $0.238(0.156)^{\mathrm{c}}$ & 1.95 & $1.05 / 1.3$ \\
Developing World & & & & \\
Beijing & 12.4 & 0.025 & & $0.16 /$ \\
Bombay & 15.1 & 0.039 & 0.5 & $0.25 / 0.25$ \\
Cairo & 9.7 & 0.097 & 0.5 & $0.60 / .25$ \\
Calcutta & 11.7 & 0.043 & & $0.28 /$ \\
Delhi & 9.9 & 0.168 & 1.2 & $1.1 / 0.62$ \\
Karachi & 9.9 & 0.066 & & $0.4 /$ \\
Shanghai & 15.1 & 0.010 & & $0.06 /$ \\
Tehran & 6.8 & 0.066 & & $0.4 /$ \\
Tianjin & 10.7 & 0.027 & 1.6 & $0.17 / 0.82$ \\
Average Developing World & & 0.060 & 0.95 & $0.38 / 0.49$ \\
\hline
\end{tabular}

${ }^{\text {a }}$ Multiplied by 2 to account for urban area mismatch in population and waste.

${ }^{\mathrm{b}} \mathrm{C}$ values are based on assuming the developed world value is 0.156 vehicles per person or $1.950 \mathrm{~kg}$ of waste per day per person.

${ }^{\mathrm{c}}$ Average in parentheses ignores Los Angeles.

Table 11. Carbon dioxide emissions as a measure of combustible material per capita.

\begin{tabular}{|c|c|c|c|}
\hline Country & $\begin{array}{l}\mathrm{CO}_{2} \text { emissions } 2002 / 1980 \text {, } \\
\text { metric ton- Carbon/person } \\
\text { (Marland et al., 2005) }\end{array}$ & $\begin{array}{l}\% \text { urban 2000/1980 } \\
\text { (United Nations } \\
\text { Secretariat, 2006) }\end{array}$ & Inferred $\mathrm{C}^{\mathrm{e}}$ \\
\hline \multicolumn{4}{|l|}{ Developed world } \\
\hline Central Europe ${ }^{\mathrm{c}}$ & $2.03 / 2.40$ & & 1 \\
\hline Oceania $^{\mathrm{d}}$ & $2.74 / 2.25$ & $74(71)$ & 1.4 \\
\hline U.S. & $5.52 / 5.48$ & $77(75)^{\mathrm{a}}$ & 2.8 \\
\hline Western Europe & $2.05 / 2.17$ & $73(69)^{b}$ & 1 \\
\hline \multicolumn{4}{|l|}{ Developing world } \\
\hline China & $0.74 / 0.41$ & $36(20)$ & 0.37 \\
\hline Egypt & $0.59 / 0.28$ & $54(44)$ & 0.3 \\
\hline India & $0.32 / 0.14$ & $41(23)$ & 0.16 \\
\hline Iran & $1.50 / 0.81$ & $64(50)$ & 0.75 \\
\hline Pakistan & $0.2 / 0.1$ & $33(28)$ & 0.1 \\
\hline Average developing world & & & 0.33 \\
\hline
\end{tabular}

${ }^{a}$ North America ${ }^{b}$ Europe ${ }^{c}$ includes former USSR ${ }^{d}$ includes Japan ${ }^{\mathrm{e}}$ Assumes $\mathrm{CO}_{2}$ emissions for the Developed World is 2.0 metric ton-C/person.

per person in developed countries has not changed significantly (Table 11). The steady carbon dioxide emissions suggest that the per capita inventory of stored fossil fuels has remained relatively stable. By comparison, the volume of sawn wood used per capita in the developed world declined to about $78 \%$ of its 1980 value by 2000 (FAOSTAT, 2005). This decline, however, was offset by a large increase in the amount of plywood, pressboard, and similar building products in use. Accordingly, the overall per capita consumption of such materials has changed by less than $10 \%$. For 
Table 12. Human Appropriation of Net Primary Productivity (HANPP) (Imhoff et al., 2004).

\begin{tabular}{ll}
\hline Location & HANPP (metric ton-Carbon/yr ) \\
\hline Africa & 2.08 \\
East Asia & 1.37 \\
North America & 5.40 \\
South America & 3.11 \\
South Central Asia & 1.21 \\
Western Europe & 2.86 \\
\hline
\end{tabular}

the U.S., per capita utilization of wood products remained approximately constant from 1960 to 1995 (Matos, 1998). Turco (1986) predicted that plastics use in the developed world would double by the year 2000. Indeed plastics consumption per capita in the U.S. doubled between 1980 and 1995 (Matos, 1998). Doubling the plastics inventory in Table 8 leads to an increase in the soot emission factor from $0.016 \mathrm{~g}$ (soot) $/ \mathrm{g}$ (fuel) to $0.018 \mathrm{~g}$ (soot) $/ \mathrm{g}$ (fuel), suggesting that $C$ could be increased by about $13 \%$ to correct for increased plastics usage worldwide.

An issue that was widely discussed in previous work is the extent of smoke rainout in fire-driven convective columns (Pittock et al., 1985; Turco et al., 1990). Here, we adopt a baseline value for the rainout parameter, $R$ (the fraction of the smoke emission not removed), of 0.8 , following Turco et al. (1990). This relatively high value for $\mathrm{R}$ implies inefficient removal of smoke in the pyrocumulus systems driven by an urban fire. Observations of such convection associated with forest fires are consistent with smoke particle over-seeding of capping cumulus clouds, which severely inhibits induced precipitation. As a consequence, essentially no smoke removal is observed in pyrocumulus plumes that stabilize below about $5 \mathrm{~km}$ (Andreae et al., 2004). According to Andreae et al. (2001) in natural fires the ratio of injected smoke aerosol larger than $0.1 \mu \mathrm{m}$ to enhanced carbon monoxide concentrations is in the range $5-20 \mathrm{~cm}^{3} / \mathrm{ppb}$ near the fires. Jost et al. (2004) found ratios $\sim 7$ in smoke plumes deep within the stratosphere over Florida that had originated a few days earlier in Canadian fires, implying that the smoke particles had not been significantly depleted during injection into the stratosphere (or subsequent transport over thousands of kilometers in the stratosphere). Such evidence is consistent with the choice of $\mathrm{R}=0.8$ for smoke removal in pyroconvection.

Smoke might also be removed by rainfall after the smoke has been dispersed and no longer is concentrated enough to inhibit precipitation. Evidence suggests that this wet removal is very efficient. For example, observations at altitudes near $10 \mathrm{~km}$ of smoke plumes processed by deep tropical convective systems remote from originating fires have yielded smoke to $\mathrm{CO}$ ratios of about $1 \mathrm{~cm}^{3} / \mathrm{ppb}$ (Andreae et al., 2001), suggesting extensive rainout of the aged accumu- lation mode smoke aerosol. This efficient removal in the troposphere is avoided in the studies of Robock et al. (2007) because solar heating quickly drives the smoke into the stratosphere where rainfall does not occur.

\subsection{Altitudes of smoke columns}

Smoke can be scavenged by rainfall, which declines rapidly with altitude and essentially ceases above the tropopause. It follows that the altitude of smoke injection and stabilization plays an important role in determining the overall lifetime of injected smoke material. There are two mechanisms controlling the altitude to which smoke will rise. The first is lofting by pyro-convection occurring above large combustion zones. A substantial observational and theoretical database is being developed based on pyro-convection seen in forest fires and convective simulations for intense heat sources. The second lofting mechanism is solar heating of elevated smoke plumes. Here, some observational evidence also indicates such lofting in nature. In relation to the present work, Robock et al. (2007) discuss indications of strong self-lofting in their numerical simulations of large smoke plumes, and provide information that illustrates the role of pyro-cumulus injection height on subsequent scavenging rates.

Following a nuclear explosion the nuclear fireball rises to its peak altitude in a few minutes. For the $15 \mathrm{kt}$ explosions investigated here the nuclear fireball is expected to rise to about $6 \mathrm{~km}$ as discussed previously (Glasstone and Dolan, 1977). However, the fires generated by the explosion take several hours to fully develop. Hence the injection height of the smoke is controlled by the energy release from the burning fuel not from the nuclear explosion. The energy released in a fire initiated by a nuclear explosion is much greater than that released by the explosion itself. About 39\% of the yield energy of a nuclear explosion is converted to heat, which can contribute to the lofting of the fireball. Hence a $15 \mathrm{kt}$ explosion releases about $2.4 \times 10^{13} \mathrm{~J}$ of thermal energy. In Hiroshima, about $13 \mathrm{~km}^{2}$ of fuel was ignited by the $15 \mathrm{kt}$ explosion (Isikawa and Swain, 1981). Assuming a fuel loading of $16 \mathrm{~g} / \mathrm{cm}^{2}$ with an energy content of air-dried wood $\left(15 \times 10^{3} \mathrm{~J} / \mathrm{g}\right)$, the energy release from the Hiroshima fires would have been about $3 \times 10^{16} \mathrm{~J}$. This is more than 1000 times greater than the energy release from the atomic explosion. Not only is the energy output by combustion much greater than from the detonation itself, the energy is released over a period of several hours, leading to efficient convective pumping.

The nuclear explosion at Hiroshima occurred at about 08:15 a.m. local time. According to Isakawa and Swain (1981) it took about $30 \mathrm{~min}$ for the fires to become widespread. A violent mass fire (sometimes called a firestorm) with strong winds occurred from 11:00 a.m. to 03:00 p.m. The winds calmed at around 05:00 p.m. Therefore, the fuel load was consumed over a period between 4 and $9 \mathrm{~h}$. Assuming all the fuel was burned in $4 \mathrm{~h}$ the power 
release would have been about $2 \times 10^{6} \mathrm{MW}$. Per unit area the energy release rate was $1.7 \times 10^{5} \mathrm{~W} / \mathrm{m}^{2}$, or about 130 times the solar constant. Similar energy release rates have been computed for the Hamburg mass fire and for simulated fires in large cities attacked with nuclear weapons (Pittock et al., 1985).

Forest fires can approach the same energy release as mass fires. Westphal et al. (1991) investigated a very large Canadian fire, which they estimated produced about $0.45 \mathrm{Tg}$ of smoke. The Canadian fire apparently consumed $95 \%$ of the biomass, taken to be $1.5 \mathrm{~g} / \mathrm{cm}^{2}$, over $720 \mathrm{~km}^{2}$ of forest during a period of $24 \mathrm{~h}$. The energy release rate was therefore about $1.9 \times 10^{6} \mathrm{MW}$ averaged over $24 \mathrm{~h}$, which is comparable to the Hiroshima energy release rate discussed above, although spread over 50 times the area.

Much interest in plume rise was directed at the Kuwati oil fires set by Iraqi forces in 1991. Small (1991) estimated that oil well fires produce energy at a rate of about $300 \mathrm{MW}$. Since the wells were separated by roughly $1 \mathrm{~km}$, they represent a very small energy source relative to either forest fires or mass fires such as occurred in Hiroshima. Hence these oil well smoke plumes would be expected to be confined to the boundary layer, and indeed were observed within the boundary layer during the Persian Gulf War.

There have been numerous observations of elevated smoke plumes from large fires. For example, the Canadian fire plume discussed by Westphal and Toon (1991) was estimated to have a top near $5 \mathrm{~km}$. A similar Canadian smoke plume was studied by Colarco et al. (2004) who estimated that the original smoke plume penetrated to heights as great as $6 \mathrm{~km}$. Studies by Fromm and Servranckx (2003) show that intense forest fires, in conjunction with deep convection can place smoke deep into the stratosphere. Lavoué et al. (2000) determined a linear relationship between frontal fire intensity, and height of the smoke injection based on forest fire data. For intense crowning fires in Canada they suggest that the injections typically reach an altitude near the tropopause, with an average local injection height of $7.7 \mathrm{~km}$. There are also limited observations of smoke plume heights following mass fires. The Hamburg convective cloud was estimated to have a top near $9 \mathrm{~km}$ (Ebert, 1963).

While these data suggest that smoke plumes above intense fires can rise to high altitude, they do not address the issue of whether specific meteorological conditions are necessary. Trentmann et al. (2006) and Luderer et al. (2006) numerically investigated the plume rise from a fire in Alberta, Canada near Chisholm during 2001 that placed smoke directly into the lower stratosphere. The Chisholm fire line was estimated to be about $25 \mathrm{~km}$ long, and about $0.5 \mathrm{~km}$ wide. As is typical of forest fires, but not nuclear mass fires of the sort expected in urban areas, the fire line propagated, in this case at a velocity near $1.5 \mathrm{~m} / \mathrm{s}$. Trentmann et al. (2006) and Luderer et al. (2006) show that the pyro-convection at Chisholm was driven by instability in the atmosphere and depended on special meteorological circumstances. However, their sim-

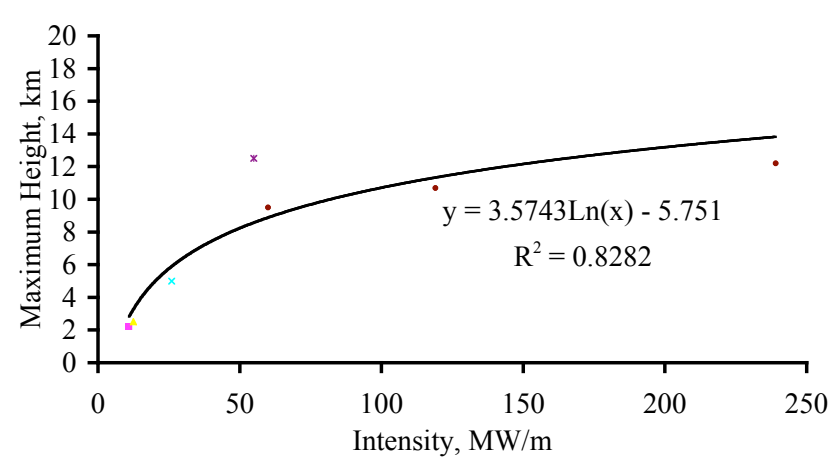

Fig. 10. Smoke plume heights from forest fires versus the fire line intensity. The red and yellow boxes and the blue and red x's are the Kruger, Internation Crown Fire, Bor Forest and Red Lake fires studied by Lavoué et al. (2000). The red circles are the computations from Luderer et al. (2006). A logarithmic fit to the data is shown by the solid line, whose equation is given on the figure.

ulations suggest that the plume rise is not sensitive to the amount of moisture in the fuel, nor to the presence of large numbers of aerosols in the plumes.

Figure 10 combines the plume rise data from Lavoué et al. (2000) with the calculations of Trentmann et al. (2006) and Luderer et al. (2006) for varying energy release rates. The calculations of Trentmann et al. (2006) and Luderer et al. (2006) suggest that the linear relationship between height and fire line intensity suggested by Lavoue et al. (2000) breaks down near the tropopause. Forest fires may have a difficult time moving smoke deep into the stratosphere via pyroconvection. The midlatitude lower stratosphere has potential temperatures that allow air to be transported horizontally into the equatorial troposphere so material injected into the lower stratosphere tends to be removed within a few months. However, material injected above about $18 \mathrm{~km}$ has potential temperatures that are high enough to cause material to remain inside the stratosphere at all latitudes, and thus have a much longer residence time. Observations clearly show that forest fire smoke does quickly reach the deep stratosphere where it will have a long residence time (Jost et al., 2004; Fromm and Servranckx, 2003; Fromm et al., 2000).

Several numerical modeling studies have been conducted to investigate the altitude of the rise of the smoke plume from a mass fire (Fig. 11). Penner et al. (1986) simulated fires of several physical sizes and energy release rates. They compared models and simulations for the Hamburg fire, which suggested a plume peak altitude just above the fire of $12 \mathrm{~km}$, and downwind of $8 \mathrm{~km}$, in agreement with the limited observations available (Fig. 11). Small and Heikes (1988) studied nuclear generated mass fires of radii larger than $5 \mathrm{~km}$. The atmospheres considered had stable lapse rates throughout the troposphere. The simulated smoke plumes for the more intense fires had tops well into the stratosphere, though the bases of the smoke plumes were near $4 \mathrm{~km}$. Small and Heikes 


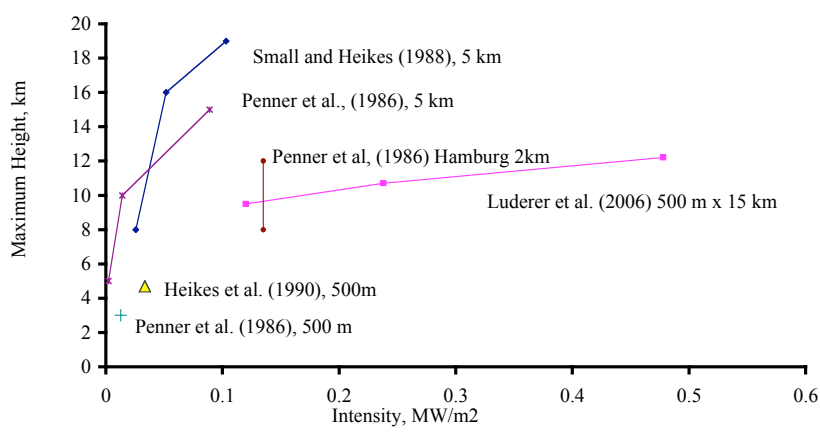

Fig. 11. Heights of plumes from mass fires with varying radius, compared with the heights from a forest fire as a function of area intensity.

found that for these large fires the smoke plume height was not sensitive to the area of the fire, and was mainly a function of the rate of energy release per unit area. Penner et al. (1986) had also carried out simulations for such large fires, assuming a stable lapse rate, and found similar results as Small and Heikes (refer to Fig. 11). By contrast, Heikes et al. (1990) showed that for fires with radii below $500 \mathrm{~m}$, the size of the fire had a significant affect on the altitude of plume rise. Penner et al. (1986) calculated similar plume rise heights as Heikes et al. (1990) for $500 \mathrm{~m}$ radius fires (Fig. 11).

The maximum plume rise altitudes for mass fires studied by Penner et al. (1986), Small and Heikes (1988) and Heikes et al. (1990) are compared with the simulations of the Chisholm fire by Luderer et al. (2006) in Fig. 11. For the Chisholm fire, we converted the line intensity into an equivalent areal intensity by dividing by the width of the fire line, which was taken to be $500 \mathrm{~m}$. The comparison suggests, following Heikes et al. (1990), that the fire radius plays an important role in the altitude reached by the smoke plume. For fires whose diameters exceed an atmospheric scale height (about $10 \mathrm{~km}$ ), deep penetration of the tropopause and lower stratosphere occurs by pyro-convection. On the other hand, pyro-convection induced by fires with dimensions well below an atmospheric scale height - such as line fires in forests, and the Hamburg mass fire - place smoke primarily in the middle and upper troposphere.

As illustrated by Trentmann et al. (2006) and Luderer et al. (2006) large forest fires may inject smoke into the lower stratosphere through pyro-convection. However, Jost et al. (2004) and Fromm et al. (2000) observed smoke deep within the stratosphere. Simulations using mesoscale models suggest that smoke from forest fires, which is detrained from the pyro-convection, is able to rise further by motion induced by solar heating of the smoke (G. Stenchikov, private communication, 2006; E. J. Jensen, private communication, 2006). Robock et al. (2007), in an accompanying paper, show that such lofting also occurs in global scale simulations forced by the smoke from a regional nuclear conflict.
We conclude that mass fires in urban areas ignited by $15-\mathrm{kt}$ sized explosions are likely to have smoke plumes rising into the upper troposphere, although the initial smoke plumes are unlikely to penetrate the tropopause unless the fire radius exceeds several kilometers. Further numerical simulations of mass fires of a few kilometers radius would be useful to better understand the behavior of pyro-convection for fires of this scale, and the dependence of plume rise on ambient meteorology. It should be noted that Figs. 10 and 11 refer to the peak altitude of the smoke plume. As illustrated by Penner et al. (1986), and Small and Heikes (1988) among others, smoke is detrained over a wide range of altitudes. Even for fires with tops well into the stratosphere, a substantial fraction of the smoke emissions are detrained in the troposphere. Once lofted into the upper troposphere, however, further lofting of the smoke may occur due to solar heating of the smoke plume itself. As a conservative estimate of the initial smoke injection heights for the scenarios studied here, and by Robock et al. (2007) we will assume as a baseline case that smoke is uniformly injected within the $150-300 \mathrm{mb}$ layer in the upper troposphere, although higher and lower injection layers are also considered.

\subsection{Optical properties of soot particles}

There are two basic approaches to determining the optical properties of aerosols. In the first approach the aerosols are assigned mass extinction and absorption coefficients. Usually this approach is employed in climate models that do not consider an evolving size distribution. The alternative approach is to assign optical constants and a size distribution. Then as the particle size evolves the aerosol optical properties can be computed interactively. Unfortunately, smoke aerosols can have a wide range of properties, and they can have complex shapes making it difficult to precisely determine their optical properties. Here we have estimated the mass of elemental carbon (also referred to as light absorbing carbon, soot, and black carbon) emitted by the fires. Most treatments of atmospheric aerosols subdivide smoke into elemental carbon, which is assumed to be absorbing at visible wavelengths, and other components, which is meant to represent materials in the smoke that do not absorb sunlight. The elemental carbon has a greater impact on climate per unit mass than the other components because it absorbs light rather than simply scattering it, but the other materials can also enhance the absorption by the elemental carbon. While our analysis of emissions ignores the other components of the smoke, they will augment the climate effects as outlined below.

Because of the importance to the climate of biomass combustion aerosols in the atmosphere there is a vast literature on their properties. Bond and Bergstrom (2006) exhaustively reviewed our understanding of the optical properties of freshly emitted, uncoated, light absorbing carbon. They conclude that the mass absorption coefficient of freshly emitted 
light absorbing carbon at mid-visible wavelengths $(550 \mathrm{~nm})$ is $7.5 \pm 1.2 \mathrm{~m}^{2} / \mathrm{g}$. This value compares well with the $7 \mathrm{~m}^{2} / \mathrm{g}$ value chosen by Turco et al. (2000), for elemental carbon generated in nuclear conflicts. The single scattering albedo of such light absorbing carbon is about 0.2-0.3 (Bond and Bergstrom, 2006), due in part to the small particle sizes of the carbon particles, which are typically smaller than $100 \mathrm{~nm}$. The refractive index of light absorbing carbon is estimated to be about 1.95 for the real index and 0.79 for the imaginary refractive index. These refractive index values may be nearly independent of wavelength in the visible wavelength range, which leads to a mass absorption coefficient for smoke that declines linearly with the inverse wavelength from 0.4 to $1 \mu \mathrm{m}$ wavelength (e.g. Bergstrom et al., 2002). As discussed by Bond and Bergstrom (2006) the use of Mie theory for spherical particles does not allow one to produce mass absorption coefficients as high as $7.5 \mathrm{~m}^{2} / \mathrm{g}$ using reasonable densities for carbon. Hence it is common for climate models to underestimate the mass absorption coefficient for fresh carbon. Robock et al. (2007), for example, use a model that produces a mass absorption coefficient of $6.2 \mathrm{~m}^{2} / \mathrm{g}$.

While the optical properties of light absorbing carbon are reasonably well constrained, it is more difficult to determine how they evolve in the atmosphere, and how the optical properties are affected by the presence of other materials in the smoke. There are essentially three ways in which the properties may evolve or be augmented by additional materials. First, the light absorbing aerosols may be externally mixed with other non-absorbing aerosols. In this case the extinction optical depth will be the sum of that from the two types of particles, but the absorption optical depth will remain the same. External mixtures may not be very common. Second, the light absorbing aerosols may become coated with other materials that do not themselves absorb visible light. It is likely that soot will be coated by sulfates in the stratosphere. Many aged tropospheric biomass combustion aerosols also are coated with various organics, sulfates and other materials. In the case of coatings the absorption by the aerosols can be increased over that of pure carbon. Bond and Bergstrom (2006) suggest that coatings typically increase the absorption by about $50 \%$. It has been shown that core/shell models (e.g. Toon and Ackerman, 1981; and Ackerman and Toon, 1981) can reproduce the optical properties of these coated materials. Finally the light absorbing aerosols may coagulate with other light absorbing aerosols to produce chains or sheets of particles. Unlike the case for spheres, it is found that the optical properties of sheets or chains do not vary greatly with size (Nelson, 1989; Bond and Bergstrom, 2006). While the mass absorption coefficient for particles smaller than about $0.1 \mu \mathrm{m}$ is similar for soot aggregates and spheres, for particles larger than $0.1 \mu \mathrm{m}$ it is much higher for aggregates. If the aggregates collapse into more compact forms, perhaps due to humidification, their absorption is reduced. In summary, if the newly emitted soot is coated with nonabsorbing material, it will be much more absorbing than pure soot, and
Table 13. Estimated fatalities, and soot generation for $5015-\mathrm{kt}$ detonations in urban zones.

\begin{tabular}{lll}
\hline Country & $\begin{array}{l}\text { Total Soot Generation } \\
(\mathrm{Tg})\end{array}$ & $\begin{array}{l}\text { Average Fuel Loading } \\
\left(\mathrm{g} / \mathrm{cm}^{2}\right)\end{array}$ \\
\hline Argentina & 1.41 & 13 \\
Brazil & 2.22 & 21 \\
China & 5.22 & 50 \\
Egypt & 2.63 & 25 \\
France & 1.05 & 10 \\
India & 3.67 & 35 \\
Iran & 2.4 & 23 \\
Israel & 0.85 & 8 \\
Japan & 1.92 & 19 \\
Pakistan & 2.9 & 28 \\
Russia & 1.89 & 18 \\
UK & 0.91 & 9 \\
U.S. & 1.2 & 12 \\
\hline
\end{tabular}

will also have a higher extinction optical depth. If the soot instead agglomerates into chains, its optical properties may not change much over time due to coagulation, unless the chains collapse.

There are many observations of biomass burning aerosols in the atmosphere. Reid et al. $(2004,2005)$ review the optical properties and particle sizes of smoke in the atmosphere. Generally it is found that the particles are near $0.1-0.2 \mu \mathrm{m}$ in diameter and morphologically "semi-spherical/semi-liquid droplets with complex cores." The liquid components are often low vapor pressure organics that survive oxidation in the flame. As the intensity of the fires increases, the liquid components decline and the emissions are dominated by complex chain aggregates. Clearly fires in an urban environment following a nuclear explosion will have a range of combustion intensities, but mass fires are likely to completely oxidize the fuels that are readily available. A second element of the smoke, but with lower mass fraction, is composed of 2-15 $\mu \mathrm{m}$ diameter ash particles. Even pieces of dirt and noncombustible material can be lofted by winds in the fire zone.

Because of the complexity of the fire environment, we have not attempted to estimate the amount of material emitted that is not elemental carbon. However any additional material probably will make the climate forcings larger than in the Robock et al. (2007) model. Added independent particles will create a mixture with the same absorption optical depth as pure carbon, but with a higher scattering optical depth. Such a mixture will lead to a larger radiative impact on climate. A situation in which the transparent material coats the carbon will lead to a larger absorption optical depth, probably by about $50 \%$, and also an increased extinction optical depth. This case will also lead to more forcing. Finally if the black carbon only coagulates with itself the forcing should remain the same as without coagulation, except for the unlikely case 
that the chains collapse, but do not become coated with another material.

\subsection{Calculations of the smoke emissions in a regional con-} flict

We use the LandScan (2003) population density database as a fuel-loading database by summing the product of $\mathrm{P}$ and $\mathbf{M}_{f}$ over a fire zone. The fuel loadings summarized in Table 13 represent averages over the fire zones in 50 target areas in various countries as an example of typical fuel loadings. For a 15-kt explosion, we assume the fire zone area is equal to that of the Hiroshima firestorm $-13 \mathrm{~km}^{2}$ - ignited by a weapon of about the same yield. The fuel loadings in Table 13 are comparable to those derived for U.S. urban cores, and old European cities at the time of WW-II as discussed above, and summarized in Fig. 9.

Using Eq. (5) we calculated the elemental carbon emitted in each target area in a number of different countries. In each case for Eq. (5) we used LandScan for P, assumed A was $13 \mathrm{~km}^{2}$, assumed Mf was $1.1 \times 10^{7} \mathrm{~g}$ fuel/person, that $\mathrm{R}$ was 0.8 , that $\mathrm{C}$ and $\mathrm{Q}$ were each unity, and that the sum of FS is $0.016 \mathrm{~g}$ soot $/ \mathrm{g}$ fuel. Figure 12 shows that different countries have different smoke emissions, and within a country the emissions differ between targets. These differences are due to variations in population density and hence fuel loading. The analysis, summarized in Table 13, suggests that an attack on a single country with $5015-\mathrm{kt}$ weapons might produce from slightly less than $1 \mathrm{Tg}$ to more than $5 \mathrm{Tg}$ of black carbonaceous smoke, after allowing for prompt rainout. Most of this "soot" would reside in the middle and upper troposphere or above, where it may be subject to further lofting (Pittock et al., 1985; Robock et al., 2007). It is possible that fuel loading in developing countries is lower than in developed countries; although not applied in deriving Table 13, a factor of 0.33-0.5 was estimated in Sect. 6.1.

Based on our analysis, U.S. urban centers targeted by 50 15-kt weapons would generate about $1.2 \mathrm{Tg}$ of elemental carbon. Small (1989) predicted that $37 \mathrm{Tg}$ of smoke would be emitted in a full scale nuclear war involving $3000 \mathrm{Mt}$ of yield detonated on 4300 targets (about 1700 of which were rural military targets), including about $50 \%$ of the U.S. urban and suburban area. The smoke production in our scenario scales almost linearly with the number of explosions in urban areas. However, the amount of smoke per kt of yield is 100 times greater for small yield weapons than for large yield weapons because fuel loading in city centers is much higher than the average over urban-suburban fuel complexes. In scenarios with large numbers of high yield weapons, many detonations either overlap or impact sparsely populated regions with very low fuel loadings.

As we discussed above there have been numerous cases in which stratospheric smoke has been observed following large forest fires. These observations rely on modern high altitude aircraft and satellites, which were not available dur- ing WWII. There were several mass fires during WWII. The best known of these were in Dresden, Hamburg, Tokyo, Hiroshima and Nagasaki. While the Dresden, Tokyo, Hiroshima and Nagasaki fires occurred within a few months of each other in 1945, the Hamburg mass fire occurred in 1943. These five fires potentially placed $5 \%$ as much smoke into the stratosphere as our hypothetical nuclear fires. The optical depth resulting from placing $5 \mathrm{Tg}$ of soot into the global stratosphere is about 0.07 , which would be easily observable even with techniques available in WWII. However $5 \%$ of that optical depth is only $3.5 \times 10^{-3}$, which would not have been possible to observe, either remotely or by in situ techniques, at that time.

There are many uncertainties in these estimated smoke emissions. We have assumed that all the fuel in the region that is attacked burns $(\mathrm{Q}=1)$, and that very little is removed in induced convection $(\mathrm{R}=0.8)$, both of these assumptions are upper limits. While the average fuel per person, $\mathbf{M}_{f}$, that we use is within $10 \%$ between different studies, we have assumed that people who live in dense urban areas have the same average as those in less developed regions. Choosing the 50 most densely populated regions in the U.S., for example, we deduce an average fuel load of $12 \mathrm{~g} / \mathrm{cm}^{2}$, while Larson and Small (1982) deduced that the fuel load in the centers of dense American cities might be $63 \mathrm{~g} / \mathrm{cm}^{2}$. There is clearly additional work that is needed to obtain more accurate estimates of the quantities of combustible materials in modern megacities, particularly in the developing world. Studies of intense forest fires indicate that the smoke from fires due to low yield nuclear weapon explosions will be injected largely into the upper troposphere. However, numerical modeling for fires of the sizes involved here would be useful, as would additional studies of natural fires. Compared with other uncertainties in the scenarios considered in the present study, such as the sizes and numbers of weapons used in a possible "small" nuclear conflict, the fuel loading, and smoke emitted are not likely to be the dominant sources of uncertainty in the environmental outcomes.

\section{Impacts on atmospheric chemistry}

The combustion of 63 to $313 \mathrm{Tg}$ of fuel will lead to the emission of $1-5 \mathrm{Tg}$ of soot, about $13 \mathrm{Tg}$ of $\mathrm{CO}$ (or $\sim 1 \%$ of the global annual source), and about $0.25 \mathrm{Tg}$ of $\mathrm{NO}$ (some tens of percent of the annual stratospheric source of $\mathrm{NO}_{\mathrm{x}}$ ) based on the emission values in Pittock et al. (1985). Large quantities of pyrotoxins will be emitted, particularly $\mathrm{CO}$, and near the fires these will be hazardous (Postol et al., 1986). However, serious global or regional scale impacts related to these gaseous emissions seem unlikely.

Stratospheric ozone loss has previously been predicted to follow the use of large numbers of high yield nuclear weapons primarily in relation to NO injected by rising fireballs. In the present case NO production is not large enough 


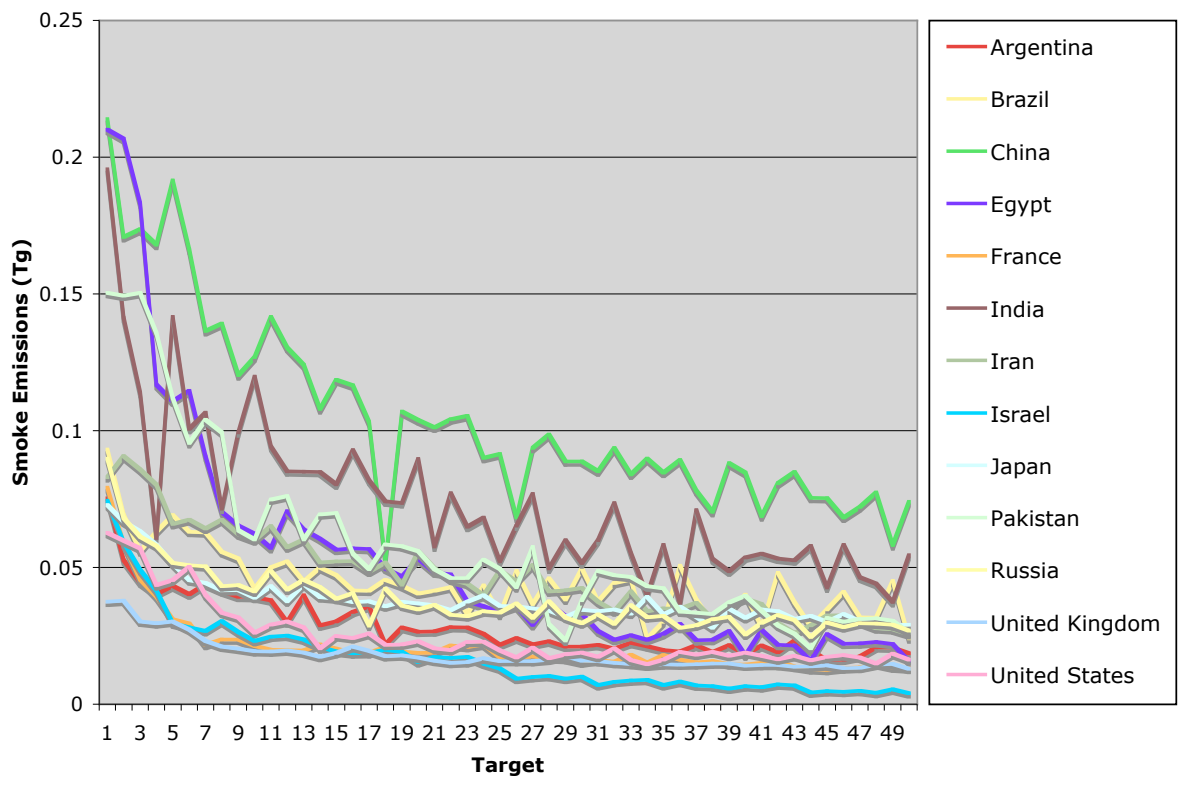

Fig. 12. Estimated carbonaceous smoke emissions per target for each of 50 targets. Smoke emissions vary between different targets because of different population densities.

to cause significant depletion of ozone. However, stratospheric soot injections, as projected here, might lead to substantial ozone perturbations. First, radiative heating by soot deposited in the upper troposphere would force ozone-poor air to rise into the stratosphere, displacing ozone-rich air (Kao et al., 1990; Robock et al., 2007). In addition, soot reaching the stratosphere would cause strong local heating of the stratosphere, which in turn would alter chemical reaction rates and further perturb stratospheric dynamics. In previous simulations of large-scale nuclear smoke clouds (Kao et al., 1990), such interactive effects reduced total ozone by $50 \%$ at some Northern Hemisphere locations, while increasing it by a similar amount at places in the Southern Hemisphere, all within 20 days of the detonations.

Soot, like other stratospheric particles, may also catalyze chemical reactions involving key species such as $\mathrm{HCl}$, leading to accelerated ozone loss. At one time it was thought that carbonaceous aerosol might be consumed by reactions with ozone (Stephens et al., 1989) and other oxidants, reducing the lifetime of soot at stratospheric altitudes. However recent data shows that the reaction probability for such loss of soot is about $10^{-11}$, so it is not an important process on times scales of several years (Kamm et al., 2004).A full simulation of stratospheric chemistry, along with additional laboratory studies, would be needed to evaluate the importance of these processes. It should be noted that rate constants for a number of potentially important reactions are lacking. Nevertheless, all the known reactions suggest that the stratospheric ozone would be lost, not gained, so that substantial stratospheric ozone depletion is a likely outcome of the scenarios studied here.

\section{Conclusions}

To an increasing extent, people are congregating in the world's great urban centers, creating megacities with populations exceeding 10 million individuals. At the same time, advanced technology has designed nuclear explosives of such small size they can be easily transported in a car, small plane or boat to the heart of a city. We demonstrate here that a single detonation in the 15 kiloton range can produce urban fatalities approaching one million in some cases, and casualties exceeding one million. Thousands of small weapons still exist in the arsenals of the U.S. and Russia, and there are at least six other countries with substantial nuclear weapons inventories. In all, thirty-three countries control sufficient amounts of highly enriched uranium or plutonium to assemble nuclear explosives. A conflict between any of these countries involving 50-100 weapons with yields of $15 \mathrm{kt}$ has the potential to create fatalities rivaling those of the Second World War. Moreover, even a single surface nuclear explosion, or an air burst in rainy conditions, in a city center is likely to cause the entire metropolitan area to be abandoned at least for decades owing to infrastructure damage and radioactive contamination. As the aftermath of hurricane Katrina in Louisiana suggests, the economic consequences of even a localized nuclear catastrophe would most likely have severe national and international economic consequences. Striking effects result even from relatively small nuclear attacks because low yield detonations are most effective against city centers where business and social activity as well as population are concentrated. Rogue nations and terrorists would be most likely to strike there. Accordingly, an organized attack on the 
U.S. by a small nuclear state, or terrorists supported by such a state, could generate casualties comparable to those once predicted for a full-scale nuclear "counterforce" exchange in a superpower conflict. Remarkably, the estimated quantities of smoke generated by attacks totaling about one megaton of nuclear explosives could lead to significant global climate perturbations (Robock et al., 2007). While we did not extend our casualty and damage predictions to include potential medical, social or economic impacts following the initial explosions, such analyses have been performed in the past for large-scale nuclear war scenarios (Harwell and Hutchinson, 1985). Such a study should be carried out as well for the present scenarios and physical outcomes.

There are many uncertainties in the analysis presented here. Some of them can be reduced relatively easily. For instance, surveys of fuel loading in developing nations would reduce the uncertainty in the amount of smoke produced by urban fires. Numerical modeling of urban mass fires, would reduce the uncertainty in smoke plume heights. Investigations of smoke removal in pyro-cumulus would reduce the uncertainty in smoke injections. The major uncertainties, however, are likely in our choices of scenario. We have considered only the casualties in urban zones, and we have assumed they would be attacked on the basis of population. Instead, one might target as many cities as possible irrespective of population in order to spread the damage, or target those with important economic assets. Military targets likely would also be to be attacked, but we have not included them in our analysis. However, we have also used a very small number of low yield weapons within the range of those controlled by the smallest current nuclear states. Larger numbers of weapons, and larger yield weapons, are possible. Many scenarios can be constructed, some of which will lead to fewer casualties, less radioactivity and less smoke emitted. The trivial example is that no effects will occur if no weapons are used. Other scenarios will lead to more casualties, more radioactivity and more smoke. Our example uses less than $0.1 \%$ of the yield of nuclear weapons that exist on the planet. For instance, a war between China and India likely would lead to more weapons of higher yield being used than assumed here. The current build up of nuclear weapons in an increasing number of states points to scenarios in the next few decades that are more extreme than the one we considered. Each of these potential hazards deserves careful analysis by governments worldwide advised by a broad section of the scientific community, as well as widespread debate.

Acknowledgements. A. Robock, G. L. Stenchikov, and L. Oman were supported by the National Science Foundation under grant ATM-0313592 and 0351280.

Edited by: W. Conant

\section{References}

Ackerman, T. P. and Toon, O. B.: Absorption of visible radiation in atmospheres containing mixtures of absorbing and nonabsorbing particles, Appl. Opt. 20, 3661-3667, 1981.

Albright, D., Berkhout, F., and Walker, W.: Plutonium and Highly Enriched Uranium 1996: World Inventories, Capabilities, and Policies, 502 pp., Oxford Univ. Press, New York, (updated http: //www.isis-online.org), 1997.

Aleksandrov, V. V. and Stenchikov, G. L.: On the modeling of the climatic consequences of the nuclear war, Proc. Applied Math., 21 pp., Computing Centre, USSR Academy of Sciences, Moscow, 1983.

Andreae, M. O., Artaxo, P., Fisher, H., Freitas, S. R., Gregoire, J. M., Hansel, A., Hoor, P., Kormann, R., Krejci, R., Lange, L., Lelieveld, J., Lindinger, W., Longo, K. , Peters, W., de Reus, M., Scheeren, B., Silva Dias, M. A. F., Strom, J., van Velthoven, P. F. J., and Williams, J.: Transport of biomass burning smoke to the upper troposphere by deep convection in the equatorial region, Geophys. Res. Lett., 28, 951-954, 2001.

Andreae, M. O., Rosenfeld, D., Artaxo, P., Costa, A. A., Frank, G. P., Longo, K. M., and Silva-Dias, M. A. F.: Smoking rain clouds over the Amazon, Science, 303, 1337-1342, 2004.

Bergstrom, R. W., Russell, P. B., and Hignett, P.: Wavelength dependence of black carbon particles: Predictions and results from the TARFOX experiment and implications for the aerosols single scattering albedo, J. Atmos. Sci., 59, 567-577, 2002.

Bond, T. C. and Bergstrom, R. W.: Light absorption by carbonaceous particles: An investigative review, Aerosol Sci. Technol., 40, 27-67, 2006.

Bouville, A., Simon, S. L., Miller, C. W., Beck, H. L., Anspaugh, L. R., and Bennett, B. G.: Estimates of doses from global fallout, Health Physics, 82, 690-705, 2002.

Bush, B. W., Dore, M. A., Anno, G. H., and Small, R. D.: Nuclear Winter Source-Term Studies Volume VI-Smoke produced by a nuclear attack on the United States, DNA-TR-86-220-V6, Defense Nuclear Agency, Alexandria, VA, 1991.

CIESIN (Center for International Earth Science Information Network), Columbia University; and Centro Internacional de Agricultura Tropical (CIAT) 2004: Gridded Population of the World (GPW), Version 3. Beta. Palisades, NY: CIESIN, Columbia University. (Available at http://sedac.ciesin.columbia.edu/gpw), 2004.

Clodfelter, M.: Warfare and Armed Conflicts a Statistical Reference, Vol II 1900-1991, 1414 pp., McFarland and Co., Jefferson, NC, 1992.

Colarco, P. R., Schoberl, M. R., Doddridge, B. G., Marufu, L. T., Torres, O., and Welton, E. J.: Transport of smoke from Canadian forest fires to the surface near Washington, D.C.: Injection height, entrainment and optical properties, J. Geophys. Res., 109, D06203, doi:10.1029/2003JD004248, 2004.

Crutzen, P. J. and Birks, J. W.: The atmosphere after a nuclear war: Twilight at noon, Ambio, 11, 114-125, 1982.

Daugherty, W., Levi, B., and Von Hippel, F.: Casualties due to the blast, heat, and radioactive fallout from various hypothetical nuclear attacks on the United States, in: The Medical Implications of Nuclear War, edited by: Solomon, F. and Marston, R. Q., National Academy of Sciences, Washington, D.C., 1986.

Decker, E. H., Elliott, S., Smith, F. A., Blake, D. R., and Rowland, F. S.: Energy and material flow through the urban ecosystem, 
Ann. Rev. Energy Environ., 25, 685-740, 2000.

Ebert, C. H. V.: The meteorological factor in the Hamburg fire storm, Weatherwise, 16, 70-75, 1963.

Ellis, J.: World War II A statistical survey, 315 pp., Facts on file, New York, 1993.

EMI (Earthquakes and Megacities Initiative): Tehran, Iran, disaster risk management profile, (Available at http://www.pdc.org/emi/ emidisplaycityprofile.html), CP-Tehran-July2006.pdf, 2006.

FAOSTAT: faostat.fao.org forestry data, updated February 2005, 2005.

Fromm, M. D., Alfred, J., Hoppel, K., Hornstein, J., Bevilacqua, R., Shettle, E., Servranckx, R., Li, Z., and Stocks, B.: Observations of boreal forest fire smoke in the stratosphere by POAM III, SAGE II, and lidar in 1988, Geohpys. Res., Lett., 27, 1407-1410, 2000.

Fromm, M. D. and Servranckx, R.: Transport of forest fire smoke above the tropopause by supercell convection, Geophys. Res. Lett., 30, 1542, doi:10.1029/2002GL016820, 2003.

Gibson, J. N.: Nuclear Weapons of the United States, 236 pp., Schiffer Pub. Ltd., Atglen, PA, 1996.

Glasstone, S. and Dolan, P. J.: The Effects of Nuclear Weapons, 3rd ed., 653 pp., United States Department of Defense, and Energy Research and Development Administration, Washington, D.C., 1977.

Harwell, M. A.: Nuclear Winter: The Human and Environmental Consequences of Nuclear War, 179 pp., Springer-Verlag, New York, 1984.

Harwell, M. A. and Hutchinson, T. C.: Environmental Consequences of Nuclear War Vol II Ecological and Agricultural Effects, SCOPE-28, 523 pp., Wiley, Chichester, England, 1985 (Second ed. 1989).

Heikes, K. E., Ransohoff, L. M., and Small, R. D.: Numerical simulation of small area fires, Atmos. Environ. 24A(2), 297-307, 1990.

Imhoff, M. L., Bounoua, L., Ricketts, T., Loucks, C., Harriss, R., and Lawrence W. T.: Global patterns in human consumption of net primary production, Nature, 429, 870-873, 2004.

Ishikawa, E. and Swain, D. L. (Translators): Hiroshima and Nagasaki the Physical, Medical, and Social Effects of the Atomic Bombings, 702 pp., Basic Books, New York, 1981.

Jost, H. J., Drdla, K., Stohl, A., Pfister, L., Loewenstein, M., Lopez, J. P., Hudson, P. K., Murphy, D. M., Cziczo, D. J., Fromm, M., Bui, T. P., Dean-Day, J., Gerbig, C., Mahoney, M. J., Richard, E. C., Spichtinger, N., Pittman, J. V., Weinstock, E. M., Wilson, J. C., and Xueref, I.: In-situ observations of mid-latitude forest fire plumes deep in the stratosphere, Geophys. Res. Lett., 31, L11101, doi:10.1020/2003GL019253, 2004.

Kamm, S., Saathoff, H., Naumann, K.-H., Mohler, O., and Schurath, U.: Gasification of a soot aerosol by $\mathrm{O} 3$ and $\mathrm{NO} 2$ :Temperature dependence of the reaction probability, Combustion and Flame, 138, 353-361, 2004.

Kao, C. J., Glatzmaier, G. A., and Malone, R. C.: Global threedimensional simulations of ozone depletion under postwar conditions, J. Geophys. Res., 95, 22 495-22 512, 1990.

Kumar, S. and Rao, C. V. S. K.: Fire loads in office buildings, J. Struct. Eng., 123(3) 365-368, 1997.

LandScanTM Global Population Database: Oak Ridge, TN: Oak Ridge National Laboratory, available at: http://www.ornl.gov/ landscan/, 2003.
Larson, D. A. and Small, R. D.: Analysis of the Large Scale Urban Fire Environment, Part II. Parametric Analysis and Model City Simulations, Pacific-Sierra Res. Corp, Contract EMW-C-0747, Work Unit 2564E, 1982.

Lavoué, D., Liousse, C., Cachier, H., Stocks, B. J., and Goldammer, J. G.: Modeling of carbonaceous particles emitted by boreal and temperate wildfires at northern latitudes, J. Geophys. Res., 105, 26871-26890, 2000.

Lavoy, P. R., and Smith, S. A.: The risk of inadvertent nuclear use between India and Pakistan, Strategic Insight, II(2), (Available at http://www.ccc.nps.navy.mil/si/feb03/southsia2.asp), 2003.

Leaning, J.: Burn and blast casualties: Triage in nuclear war, in: The Medical Implications of Nuclear War, edited by: Solomon, F. and Marston, R. Q., pp. 167-203, National Academy of Sciences, Washington, D.C., 1986.

Lucas, K. A., Orient, J. M., Robinson, A., Maccabe, H., Morris, P., Looney, G., and Klinghoffer, M.: Efficacy of bomb shelters: with lessons from the Hamburg firestorm, Southern Medical J. 83, 812-820, 1990.

Luderer, G., Trentmann, J., Winterrath, T., Textor, C., Herzog, M., Graf, H. F., and Andreae, M. O.: Modeling of biomass smoke injection into the lower stratosphere by a large forest fire (Part II): Sensitivity studies, Atmos. Chem. Phys. Discuss., 6, 60816124, 2006, http://www.atmos-chem-phys-discuss.net/6/6081/2006/.

Maheri, M. R.: Performance of building roofs in the 2003 Bam, Iran, earthquake, Earthquake Spectra, 21(S1), S411-S424, 2005.

Marland, G., Boden, T. A., and Andres, R. J.: Trends: A Compendium of Data on Global Change, Carbon Dioxide Information Analysis Center, Oak Ridge National Laboratory, D.O.E., Oak Ridge, Tenn. (http://cdiac.esd.ornl.gov/trends/emis/ em_cont.htm), 2005.

Matos, G. and Wagner, L.: Consumption of materials in the United States 1900-1995, Ann. Rev. Energy Environ., 23, 107-122, 1998.

McKinzie, M., Mian, Z., Nayyar, A. H., and Ramana, M. V.: The risks and consequences of nuclear war in South Asia, in Out of the Nuclear Shadow, edited by S. Kothari, and Z. Mian, pp 185196, Zed Books Ltd., London, 2001.

Middleton, H.: Epidemiology: The future is sickness and death. Ambio 11, 100-105, 1982.

National Academy of Sciences: Monitoring Nuclear Weapons and Nuclear-Explosive Materials, 250 pp., National Academy of Sciences, Washington, D.C., 2005.

Nelson, J.: Fractality of sooty smoke: Implications for the severity of nuclear winter, Nature, 339, 611-613, 1989.

Norris, R. S. and Arkin W. M.: Known nuclear tests worldwide, 1945-98, Bull. Atomic Scientists, 54(6), 65-67, 1998.

Norris, R. S. and Kristensen, H. M.: Global nuclear stockpiles, 1945-2002, Bull. Atomic Scientists, 58(6), 103-104, 2002.

Norris, R. S. and Kristensen, H. M.: Chinese nuclear forces, 2003, Bull. Atomic Scientists, 59(6), 77-80, 2003.

Norris, R. S. and Kristensen, H. M.: Russian nuclear forces, 2005, Bull. Atomic Scientists, 61(2), 70-72, 2005a.

Norris, R. S. and Kristensen, H. M.: North Korea's Nuclear Program, 2005, Bull. Atomic Scientists, 61(3), 64-67, 2005b.

Norris, R. S. and Kristensen, H. M.: French nuclear forces, 2005, Bull. Atomic Scientists, 61(4), 73-75, 2005c.

Norris, R. S. and Kristensen, H. M.: India's nuclear forces, 2005 , 
Bull. Atomic Scientists, 61(5), 73-75, 2005d.

Norris, R. S. and Kristensen, H. M.: British nuclear forces, 2005, Bull. Atomic Scientists, 61(6), 77-79, 2005e.

Norris, R. S. and Kristensen, H. M.: U.S. nuclear forces, 2005, Bull. Atomic Scientists, 61(1), 73-75, $2005 f$.

Norris, R. S. and Kristensen, H. M.: Global nuclear stockpiles, 1945-2006, Bull. Atomic Scientists 62(3), 60-63, 2006.

Nuclear Energy Agency: Chernobyl: Assessment of Radiological and Health Impacts, 2002 Update of Chernobyl 10 years On, 155 pp., Nuclear Energy Agency OECD Publications, Paris, France, 2002.

Oughterson, A. W. and Warren, S.: Medical Effects of the Atomic Bomb in Japan, 477 pp., McGraw-Hill, New York, 1956.

OTA: The Effects of Nuclear War, Office of Technology Assessment, Washington, DC., 1979.

Peczkis, J.: Initial uncertainties in "Nuclear winter": A proposed test based on the Dresden firestorm, Clim. Change, 12, 199-208, 1988.

Penner, J. E., Hassleman Jr., L. C., and Edwards, L. L.: Smokeplume distributions above large-scale fires: Implications for simulations of "nuclear winter", J. Clim. Appl. Meteorol., 25, 14341444, 1986.

Pittock, A. B., Ackerman, T. P., Crutzen, P. J., MacCraken, M. C., Shapiro, C. S., and Turco, R. P.: Environmental Consequences of Nuclear War SCOPE-28, Vol. 1, Physical and Atmospheric Effects, Wiley, Chichester, England, 1985 (Second ed. 1989).

Postol, T. A.: Possible fatalities from superfires following nuclear attacks in or near urban areas, in: The Medical Implications of Nuclear War, edited by: Solomon, F. and Marston, R. Q., pp. 15-72, National Academy of Sciences, Washington, D.C., 1986.

Rehm, R. G., Pitts, W. M., Baum, H. R., Evans, D. D., Prasad, K., McGrattan, K. B., and Forney, G. P.: Initial model for fires in the World Trade Center Towers, U.S. Dept. of Commerce, NISTIR 6879, 2002.

Reid, J. S., Eck, T. F., Christopher, S. A., Koopmann, R., Dubovik, O., Eleuterio, D. P., Holben, B. N., Reid, E. A., and Zhang, J.: A review of biomass burning emissions part III: intensive optical properties of biomass burning particles, Atmos. Chem. Phys. Discuss., 4, 5201-5260, 2004,

http://www.atmos-chem-phys-discuss.net/4/5201/2004/.

Reid, J. S. Koppmann, R., Eck, T. F., and Eleuterio, D. P.: A review of biomass burning emissions part II: intensive physical properties of biomass burning particles, Atmos. Chem. Phys., 5, 799825,2005 , http://www.atmos-chem-phys.net/5/799/2005/.

Robock, A., Oman, L., Stenchikov, G. L., Toon, O. B., Bardeen, C., and Turco, R. P.: Climate consequences of regional nuclear conflicts, Atmos. Chem. Phys., 7, 2003-2012, 2007, http://www.atmos-chem-phys.net/7/2003/2007/.

Schubert, J.: Examination of the Building Density and Fuel loadings in the Districts Eimsbuttel and Hammerbrook in the City of Hamburg as of July 1943, E. Molton (translator), SRI Report NRDL-TRC-68-65, OCD Work Unit No. 2536D, 1969.
Shapiro, C. S., Harvey, T. F., and Peterson, K. R.: Radioactive fallout, in: The Medical Implications of Nuclear War, edited by: Solomon, F. and Marston, R. Q., 167-203, National Academy of Sciences, Washington, D.C., 1986.

Simonett, D. S., Barrett, T. N., Gopal, S., Holsmuller, F. J., and Veregin, H.: Estimates of the magnitude and spatial distribution of combustible materials in urban areas: a case study of the San Jose Area, California, Fire and Materials, 12, 95-108, 1998.

Small, R. D.: Atmospheric smoke loading from a nuclear attack on the United States, Ambio, 18, 377-383, 1989.

Small, R. D.: Environmental impact of fires in Kuwait, Nature, 350, 11-12, 1991.

Small, R. D. and Heikes, K. E.: Early cloud formation and large area fires, J. Appl. Meteorol., 27, 654-663, 1988.

Stephens, S. L., Calvert, J. G., and Birks, J. W.: Ozone as a sink for atmospheric carbon aerosols today and following an nuclear-war, Aerosol Sci. Technol., 10, 326-331, 1989.

Toon, O. B., and Ackerman, T. P.: Algorithms for the calculation of scattering by stratified spheres, Appl. Opt., 20, 3657-3660, 1981.

Trentmann, J., Luderer, G., Winterrath, T., Fromm, M., Servranckx, R., Textor, C., Herzog, M., and Andreae, M. O.: Modeling of biomass smoke injection into the lower stratosphere by a large forest fire (Part I); Reference study, Atmos. Chem. Phys. Discuss., 6, 6041-6080, 2006,

http://www.atmos-chem-phys-discuss.net/6/6041/2006/.

Turco, R. P.: Recent assessments of the environmental consequences of nuclear war, in: The Medical Implications of Nuclear War, edited by: Solomon, F. and Marston, R. Q., 96-116, National Academy of Sciences, Washington, D.C., 1986.

Turco, R. P., Toon, O. B., Ackerman, T. P., Pollack, J. B., and Sagan, C.: Nuclear winter: Global consequences of multiple nuclear explosions, Science, 222, 1283-1292, 1983.

Turco, R. P., Toon, O. B., Ackerman, T. P., Pollack, J. B., and Sagan, C.: Climate and smoke: An appraisal of Nuclear Winter, Science, 247, 166-176, 1990.

United Nations Secretariat: World Population Prospects: The 2002 Revision and World Urbanization Prospects: The 2003 Revision, Population Division of the Department of Economic and Social Affairs of the United Nations Secretariat, (http://esa.un. org/unup), 2006.

Wallace, T. C.: The May 1998 India and Pakistan nuclear tests, Seismological Res. Lett., 69, 386-392, 1998.

Westphal, D. L. and Toon, O. B.: Simulations of microphysical, radiative, and dynamical processes in a continental-scale forest fire smoke plume, J. Geophys. Res., 96, 22 379-22 400, 1991. 